\title{
The Carcinoembryonic Antigen (CEA): Past, Present, and Future*
}

$\underline{\text { Phil Gold }} \stackrel{\text { Ý}}{\text {,C.C.,O.Q., M.D.,Ph.D., and Neil A. Goldenberg }} \underline{\text { a }}$

* Portions of this review have been published in Perspectives in Colon and Rectal Surgery 9(2); 1996.

To whom correspondence should be addressed:

Ý Clinical Research Centre, Montreal General Hospital, McGill University, Suite D13- 173, 1650 Cedar Avenue, Montreal, QC, Canada H3G 1A4.

${ }^{a}$ Faculty of Medicine, McGill University, 3655 Drummond St., Montreal, QC, Canada H3G 1Y6

\section{INTRODUCTION}

Just as Kierkegaarde observed that, "life must be understood backward [but]...lived forward" (1), so it is with science, which must be performed forward--but may be written backward. In the telling, the phenomenon of scientific revisionism unfortunately omits much of both the humanity and the enjoyment of the scientific process. "How could they have guessed that those results would be obtained?" asks the novice. With due respect to "gut" intuition, the answer is very frequently that "they" couldn't have guessed. Yet, the most exciting science is that which leads to unexpected findings and requires the eye and mind of the iconoclast to realize that new ground has been broken.

About 30 years before the writing of this article began, the first author was given the opportunity to begin a series of experiments that would lead to the discovery of CEA as a human tumor marker, and to the myriad avenues of CEA research that are being actively pursued at the present moment. As noted above, it might be very satisfying to state that these investigations were undertaken with clear insight into the potential experimental pitfalls that might be encountered and the ultimate value of the data that would be obtained. This was not quite the case, and the problems of data interpretation, confounding semantics, and personal biases were certainly not anticipated.

In the course of the work to be described, the meaning of the Kuhnian paradigm (2) and the manner in which accepted scientific constructs are defended by the "establishment" came to be appreciated first-hand. As do too many other discoveries, advances in CEA research endured the prevailing mindset that "if it's new, it's not true," "if it's true, it's not important," and "if it's new and true and important, then we knew it all the time." Yet, the controversies surrounding CEA quite fortuitously stimulated, rather than inhibited, further studies that ultimately led to some very exciting outcomes. 
The idea for the work on CEA devolved from two lectures that the first author attended in 1961-2, during a year of Rotating Internship at the Montreal General Hospital and McGill University. The first described the attempts and failures to detect either components or functions unique to cancer cells and not found in any normal tissues. The second lecture dealt with the then relatively recent description of Acquired Immunological Tolerance (3)--until 1953 only a theoretical concept--and the new perspectives that this phenomenon was creating in the understanding of the immune system and in various areas of clinical medicine. Hence, the experiments subsequently undertaken were predicated on the somewhat naive hope that the burgeoning tools of immunology, such as immunologic tolerance, would provide both the specificity and sensitivity that had been lacking in the previous efforts to find one or more specific tumor constituents in human cancer tissues.

In the 1950s, after perhaps a century of study in a variety of disciplines and using numerous technologies, the paradigm in the field was very simply that "tumor-specific materials" did not exist in cancer tissue and, moreover, that these would not be found (4). Nevertheless, by the early 1960s, studies of the rejection of well-defined transplantable tumors between highly inbred, or syngeneic, animals had clearly demonstrated the existence of tumor-specific transplantation antigens (TSTAs) in these animal models (5). Conventional wisdom of the day maintained that such artificially-generated data could hardly be applicable to outbred, "wild-type" humans. Notwithstanding this, a sizable field of investigation grew up around the question of how TSTA-bearing animal tumors escape the immune surveillance system, a question that has yet to be answered satisfactorily. It is to a field of tumor immunology in this state of flux that CEA research traces its origin.

Lacking a syngeneic human population, to say nothing of the moral and ethical prohibitions to human tumor transplantation, the initial approach taken was to investigate the absorption of antiserum against colon cancer by normal tissue, and to employ immunologic tolerance to compare colon cancer tissue with normal colonic tissue from the same donors (6). Colonic cancer was chosen as a model because this tumor does not extend intramurally beyond 5-6 cm, either proximally or distally, from the tumor tissue in the gross. Hence, normal and tumor tissues taken from the same individual at operation could be rationally compared without concern for the problem of alloantigenicity that had plagued previous studies comparing tumor and normal tissues taken from different individuals. The problem of obtaining fresh surgical specimens from the operating room without interfering with the critical process of appropriate determination of the tumor should be noted. Much gratitude is due to numerous colleagues at the Departments of Surgery and Pathology at the Montreal General Hospital for their fervent efforts to assist in this project without ever compromising patient priority and safety.

In one of the earliest series of experiments, then, adult male rabbits were immunized with colonic cancer tissue extract and the resulting antiserum was absorbed with 'an excess' of the corresponding normal material, while in a second series of studies an attempt was made to render neonatal rabbits tolerant to the normal tissue extract. These animals were subsequently immunized with the corresponding tumor material, as adults. The necessary tissue extracts and antisera now in hand, these two series of studies led, with the use of immunologic techniques as indicator systems, to the demonstration of a tumor component in colonic cancer tissue that was not found in the corresponding normal tissue (6).

In a subsequent series of studies (7), it was found that the same cancer antigen was also present in all endodermally-derived gastrointestinal tumors--from the lower esophagus, above, to the anorectal junction, below. The antigen was also demonstrable in primary tumors of the pancreas and the liver, both derivatives of the second stage of the duodenum during embryologic development. Tumors of gut origin that underwent extra-enteric metastasis to such tissues as lung, bone and brain, retained the antigenic activity in question, whereas tumors of all other organs that spread to the liver, for example, were devoid of such activity. Hence, the parameter that determined expression of the antigenic activity described was the site of tumor origin, and not the site of growth. 
During a departmental seminar in which these findings were outlined, a good deal of interest was generated by the "embryologic Confinement" of the tumor antigenic activity in question. The substance appeared to be related to cancers that arose from tissue lying between the embryologic stomatodeum, above, to the proctodeum, below. Thus, further investigations were done with human embryo- and fetus-derived tissues. Since this was done at a time well before abortion-on-demand, it took a fair amount of time to collect tissues from spontaneous abortuses at various points in pregnancy. Nevertheless, it was found that gut-derived tissue in the first two trimesters of gestation expressed the antigenic moiety of interest but that comparable tissue in the third trimester did not. Hence, the material was named the carcinoembryonic antigen(s) of the human digestive system, subsequently abbreviated to CEA (7).

The observations described above appeared in the Journal of Experimental Medicine in the first two papers on CEA, published in 1965 and 1966 (6,7). Immediately, there was expression of international interest in the reported findings, and the subsequent shipment of CEA and anti-CEA antisera to colleagues around the world allowed work on CEA to be performed in a time-frame that, otherwise, would have taken years longer for our laboratory alone.

\section{THE BIOLOGY OF CEA}

The extensions of the two initial series of studies can primarily be divided between those focused on the basic biology (localization, purification, chemical definition, functional activity and genetic control) of the CEA molecule, and those directed at answering clinical questions. As concerns the biology of CEA, early investigations involved the purification and characterization of the molecule, utilizing anti-CEA antiserum as a guide to the recovery and concentration of CEA at each stage $(8,9)$. These early studies would, years later, lead to the cloning of the CEA gene and to the present understanding of the functional biology of the CEA molecule and other members of its molecular family (see below).

The CEA molecule is an oncodevelopmental human tumor marker, and bears the Cluster Differentiation designation CD 66e (10), a subtype of the CD 66 group to which both the CEA molecule and other CEA family members belong (see below). CEA was initially found in adenocarcinomas of the human digestive system $(6,7)$ and was shown to be a membrane constituent (11). In the membrane, it demonstrates redistribution, or "capping" under appropriate experimental conditions, suggesting that the CEA molecule is a surface glycoprotein that interacts with the microskeleton of the cell $(12,13)$. From the cell surface, CEA may be released into the interstitial space and, thence, into the circulation of the tumor-bearing patient, where it can be detected by immunoassay (14).

The CEA molecule has a nominal molecular mass of $180 \mathrm{kDa}$ with a protein core that makes up somewhat less than half of the molecule $(9,15)$. As deduced from the complete sequence of the cloned CEA gene, the protein consists of a single polypeptide chain, containing a 107 amino acid $\mathrm{NH}$-terminal domain followed by three highly homologous domains of 178 amino acids each $(16,17)$. The $\mathrm{C}$-terminal domain, consisting of 26 amino acids, is processed so that CEA binds to the plasma membrane through a glycophosphatidyl inositol (GPI) anchor (18). Carbohydrate side-chains comprise the remainder, or over half, of the molecular mass bound to the protein core via 28 potential Asn-linked glycosylation sites that have been identified on the CEA molecule (16). The molecule appears as a screw- or cruller-shaped structure with dimensions of approximately 9 x $40 \mathrm{~nm}$ when visualized by electron microscopy after appropriate shadow casting (19).

Even very early immunobiochemical studies had revealed a number of molecules closely related to CEA, indicating the existence of a "CEA molecular family" (20,21). Candidates for this group included the nonspecific cross-reacting antigen (NCA), biliary glycoprotein (BGP I-II), the meconium antigen (MA), pregnancy-specific B-glycoproteins (PSG), and the tumor antigen denoted TEX. Until the CEA gene was cloned, the exact size of the CEA-related family and the relationship between family members, and still other known glycoproteins, was difficult to ascertain. Molecular weights varied depending upon the degree of 
glycosylation, degradation, or aggregation of molecular species, and variations in immunospecificity existed among the antibody probes employed in any given laboratory. The latter consideration became rather important in the semantic dialogue dealing with the designation of CEA as tumor-specific, as discussed below. The high level of glycosylation of CEA made protein sequencing a rather difficult task $(22,23)$. By extension, cloning of the CEA gene and its family members became a somewhat arduous undertaking. Nevertheless, once the technological obstacles had been overcome (23), the isolation of cDNA clones for CEA and related family members was achieved through the screening of genomic and cDNA libraries via two methods: (i) using synthetic oligonucleotides based on known CEA protein sequences; and (ii) using antiCEA antibodies to identify CEA proteins expressed in suitable vectors $(17,24-33)$.

The CEA gene family comprises 29 gene-like sequences, in two defined clusters on chromosome 19, between 19q13.1 and 19q13.3 (34-36). The PSG gene family, found in the same chromosomal region, has been defined as a sub-family of the main CEA family and is represented by 19 of the 29 gene sequences noted above (37). It is rather sobering to realize that the first author has spent the greater part of his life focused on the product of such a minuscule region of the human genome.

Complete sequence data for a number of the genes in question have been obtained and the primary structure for the peptides for which they code has been deduced for many of them (24-33). A high degree of sequence conservation between the various protein moieties of the CEA/PSG molecules suggests that they have a common genetic ancestry (38). Furthermore, protein and DNA sequence comparisons indicate that the CEA gene family is a subset of the immunoglobulin ( $\mathrm{Ig}$ ) gene superfamily with analogous variable and constant regions (39). The CEA gene itself begins with an amino terminal Ig V-like domain, followed by six Ig C2-setlike domains $(17,24-29)$.

If one examines the known members of the CEA family, they fall into two distinct groups on the basis of membrane anchorage. Some, like CEA itself, are of the GPI-linked group, while others, like BGP, appear on the cell surface with a transmembrane linkage (40). It is of interest to note that the GPI members tend to be up-regulated in human tumors, while the transmembrane group tends to show down-regulation under these circumstances $(41,42)$. In addition to the mode of membrane binding, the two subgroups of molecules represented, for example, by CEA and BGP, have very different properties. Hence, whereas the GPI-linked CEA molecule shows temperature- and $\mathrm{Ca}^{2+}$ - independence of the classical intercellular adhesion molecular type, BGP-mediated adhesion is both temperature- and cation-dependent, more characteristic of the cadherin group of molecules. Further, unlike the double reciprocal binding between two domains in CEA-CEA adhesion, that involving BGP requires only one domain (43). Finally, whereas the ectopic expression of CEA in myoblasts can block myogenic differentiation while leaving the cells with the ability to divide, similar expression of BGP does not effect, or may even accelerate, myogenic differentiation (44).

Comparative studies of CEA gene family members in mouse and man, and the observation that the nucleotide sequences of repeated domains in a given gene, and of domains in different genes, are more closely aligned $(>80 \%)$ than the analogous amino acid sequences $(>60 \%)$, suggest that the CEA gene family arose relatively recently in the evolutionary process. The gene family and its products may presently be in a state of evolutionary transition (45), which may explain some of the diverse potential functions that have been proposed for CEA and its relatives based on observations from different model systems described briefly below.

With regard to the possible functions of CEA, studies have revealed a number of fascinating possibilities. In a series of experiments employing cultured human colonic adenocarcinoma cells and rodent cells transfected with CEA cDNA, so that these cells now expressed the CEA molecule on their surfaces for the first time, it was demonstrated that CEA mediates $\mathrm{Ca}^{2+}$ - and temperature-independent aggregation, as noted above (46). Further, CEA was shown to induce the homotypic sorting of cells in heterogeneous populations of aggregating cells. Thus, CEA can be considered an intercellular adhesion molecule, in contradistinction to the 
$\mathrm{Ca}^{2+}$ - and temperature-dependent cadherins $(47,48)$.

CEA is found primarily on the lumenal aspect of epithelial cells in normal adults, albeit in very small amounts, but on basolateral cell membranes in both embryonic intestine and colonic cancer $(46,49)$. It may be that when large amounts of CEA are produced, as is the case in the developing embryonic intestine and in colonic tumors, the normal adult single palisade layer of epithelial cells is replaced with a multilayered cellular array. This could be a consequence of weaker intercellular adhesion due to a possible interference by CEA with other intercellular adhesion systems. The tight association seen between normal adult cells may be necessary for the single-layered configuration and the ordered differentiation of adult epithelial cells, which arise from the crypt stem cells and move toward the tip of the villi, where the fully differentiated cells are extruded. Disruption of this structure during tumorigenesis by the adoption of an embryo-like multilayered configuration, as either a cause or effect of the cancerous change, could disturb normal differentiation (see below) and favor the development of overt malignancy $(31,49)$. In an alternative theory, von Kleist et al. have proposed that CEA may act as a signal protein inhibiting further intercellular contact rather than as an adhesion molecule. This would foster cell migration and, thereby, the formation of metastases, as well as inhibit close contact between CEA-expressing target cells and cytotoxic effector cells of the immune system (50).

As concerns the relationship of CEA concentration to the metastatic potential of CEA-producing tumors, at least two possibilities must be examined. The first is the association of intercellular CEA concentration, or perhaps more critically that of free intercellular CEA or CEA peptides, to the strength of intercellular adhesion and, hence, to metastatic potential (51). It has also been proposed, though never demonstrated, that another parameter facilitating cancer cell implantation might be the interaction between circulating CEAbearing tumor cells and blood-borne CEA trapped on the surface of the Kupffer cells of the liver. Alternatively, circulating CEA may bind to a specific receptor on Kupffer cells, causing them to produce cytokines that stimulate the growth of metastatic cells $(52,53)$. In this regard, it is interesting to note that a serum CEA-releasing factor has recently been postulated based on the finding that a factor in human serum significantly augments the release of CEA from cultured tumor cells (54).

The molecular mechanism of CEA-CEA-mediated adhesion has been studied through the use of "designer molecules" made possible by the availability of the CEA gene. These molecules included various CEA peptides, altered CEA fragments, and hybrid molecules of CEA and the neural cell adhesion molecule (NCAM), a comparable member of the Ig gene superfamily capable of homotypic $\mathrm{Ca}^{2+}$-independent intercellular adhesion. It was found that CEA-mediated intercellular adhesion is unique for intermolecular binding between Ig superfamily members. This adhesion involves two point reciprocal binding between the $\mathrm{N}$ (Ig V-like) and A3B3 (two of the Ig C2-set-like) domains, on anti-parallel molecules of apposing CEAbearing cell surfaces (55).

To examine the possible effect of CEA on differentiation, a series of studies was performed based on the ectopic production of CEA on the myogenic differentiation of cultured L6 rat myoblasts (56). These cells differentiate and fuse into multinucleated myotubules when serum growth factors are reduced, initiating a complex myogenic differentiation program. When transfected with functional CEA cDNA, stable transfectant clones of L6 cells producing relatively modest amounts of CEA were shown to be incapable of myogenic differentiation and fusion but retained their proliferative potential. This block in differentiation was shown to be critically dependent on the double reciprocal binding between anti-parallel molecules, presumably on apposing cell surfaces, as described above. Moreover, the differentiation-block imposed by CEA could be rapidly reversed by disruption of the CEA-CEA bonds. The mechanism by which intercellular binding through CEA inhibits the differentiation pathway is presently under investigation.

It is of interest that human colonic cancer almost always develops in mucosal tissue that has already undergone multiple steps of genetic change. It has been postulated that these multiple steps create a field 
effect which is characterized by morphologically normal, but biologically altered, epithelial cells. Indeed, CEA has been used as a phenotypic marker of this field effect by examining the immunohistochemical expression of CEA on morphologically normal mucosa adjacent to colonic adenocarinomas. It has been shown very clearly that CEA expression occurs in "normal" peritumoral mucosa and that there is a gradient of CEA expression, falling off at increasing distances from the tumor (57). These data are relevant to both the biology of human colorectal cancer, and more practically, to the optimal location of surgical resection. Quite clearly, a good deal of work remains--and should be rapidly forthcoming--that promises to integrate and clarify the roles of CEA and its family members in terms of evolution, ontogeny, phylogeny, tissue architecture, invasion, and metastatic potential.

\section{THE CLINICAL ROLE OF CEA}

A role for CEA in clinical medicine first became a consideration with the development of a radioimmunoassay for circulating CEA by Thomson and colleagues in 1969 (14). The first series of data, derived from patients with established colonic cancer, were most exciting; despite warnings to the contrary, the news was soon abroad that "the definitive test for bowel cancer was at hand." When more extensive studies revealed the expected false-negative assays, particularly in early stage bowel cancer, and false positive results in patients with non-enteric cancer or other non-cancerous conditions (see below), the response of a subset of the medical and scientific communities was again inflammatory, this time swinging to the other extreme.

As an aside, it must be understood that the field of cancer research had been plagued for a very long time by the semantic dilemma surrounding the use of the adjectives "tumor-associated" and "tumor-specific" when applied to cancer cell constituents. In this context, it was de rigeur to believe that unless a substance would be found to be absolutely unique to tumor cells, it would not be very worthy of further study for either its biological function or its potential application in clinical medicine. It did not seem to matter if the information might be of help to clinicians in the diagnosis, or other aspects of care, of the cancer patient. Moreover, as noted earlier, the conventional wisdom at the time held that tumor-specific materials did not exist.

Notwithstanding the precedent of a variety of clinically-useful non-specific markers for tumors, such as Bence-Jones Protein (BJP) (58), serum immunoglobulins, and various hormones and enzymes $(59,60)$, it was debatable 25 years ago that considerations of clinical utility would succeed in increasing international interest in performing basic, and even clinical, studies dealing with CEA. Indeed, much of the subsequent CEA research was directed toward toward resolving the issue of tumor-specificity.

Since the discovery of CEA over three decades ago, a large body of literature has accumulated describing the value of serum CEA measurements in the care of cancer patients. Information concerning the clinical usefulness of CEA has also been reviewed in two major consensus conferences held in 1977 and 1980 (6163). In general, current clinical applications of CEA may be divided into the categories of detection (screening for cancer in an asymptomatic population), diagnosis (differentiating malignant from benign tumors), prognosis (staging and classification), treatment monitoring (therapeutic effect, tumor recurrence), special pathologic techniques (immunohistochemistry, immunocytochemistry), localization (imaging of tumors with radiolabeled antibodies), and therapy (antibody-linked cytotoxic agents, vaccine vectors carrying the CEA gene).

\section{CEA and Screening}

Colon cancer is the second most common fatal malignancy in North America, due in part to the late stage at which it is often diagnosed (64). In the search for tumor markers to aid in the early diagnosis of cancer, several oncodevelopmental entities have been described, most of which have limited clinical utility (65). 
Currently, the most clinically useful of these oncofetal markers is CEA. As alluded to earlier, the initial high expectations for the radioimmunoassay were tempered by the finding of elevated plasma CEA levels in several benign diseases (66-73). Today, with refinements in assay technique and the accumulation of data, it is understood that the differences in CEA levels between normal and tumor-bearing individuals are primarily, but certainly not entirely, quantitative in nature. The circulating CEA level in a given patient is the end result of various factors, including the level of gene expression, the rate of CEA synthesis, its subsequent release by the tumor, the half-life of CEA in the circulation, the degree of necrosis and vascularization of the tumor, as well as the rate of CEA catabolism by the liver. Despite the complexity of the system, the CEA assay has taken an important role in the management of patients with cancer.

Concentrations of 2.5-5.0 ng/ml (depending upon the assay used) are commonly considered cut-off points for distinguishing normal from abnormal levels of serum or plasma CEA. In two large surveys of apparently healthy persons, 85 to $87 \%$ had serum antigen levels of less than $2.5 \mathrm{ng} / \mathrm{ml}, 95$ to $98 \%$ had levels of less than $5 \mathrm{ng} / \mathrm{ml}$ and virtually no one had a level greater than $10 \mathrm{ng} / \mathrm{ml}(74,75)$. CEA concentrations are, in general, more often raised in smokers than in non-smokers $(73,76)$, and more frequently elevated in men than in women (77). The same is true for older subjects when compared with younger individuals $(78,79)$. Racial differences in the frequency of serum elevations of CEA have been suggested (80) but not established.

Although guidelines for the appropriate use of CEA assays have been reported, Fletcher (81) argues that physicians in practice apparently have greater confidence in the practical value of CEA measurements than do "experts" in the field. In one study in 1979, over 50\% of physicians believed that a CEA assay was worthwhile for initial detection of colonic cancer and that elevated serum levels of CEA in a non-smoking person without symptoms should prompt an aggressive search for colonic cancer. Both premises were questioned by investigators in the CEA field at that time (82).

Currently available CEA assays cannot be used as screening tests (strictly defined as procedures for detection of disease in asymptomatic individuals) for colorectal cancer, insofar as false-negative tests can be obtained. For example, in earlier stages of colorectal cancer (Dukes Stages A and B), CEA level is less likely to be elevated. By contrast, assays for CEA more readily detect advanced colorectal cancer of Dukes Stages C and D (74,81,83-85). Again due to the lack of sensitivity of existing tests, CEA assays perform no better in screening for other cancers commonly associated with elevated CEA levels $(86,87)$. Elevated plasma levels of CEA, or CEA-reactive materials, have been described in advanced breast cancer $(67,69,88-93)$, pancreatic cancer $(67,90,94-102)$ lung cancer $(90,103)$, and other non-colonic adenocarcinomas $(104-106)$. However, the difficulty in achieving simultaneous sensitivity and specificity of CEA assays in the context of specific cancer profiles, together with the low prevalence of cancer in asymptomatic populations, results in too many falsepositive and false-negative results to warrant the use of current CEA assays in true screening for early cancers. This is supported by data from the large, cohort, population-based Framingham study, which examined CEA levels in serum samples from patients with newly detected cancers (83), and is also in agreement with the recommendations of the National Institutes of Health Consensus Development Conference of 1981 (85).

\section{CEA as a Diagnostic Test}

In the strictest sense, diagnostic tests are used not in screening, but in "case-finding": i.e., in determining whether disease is present in individuals at high risk for, or suspected of, having the disease. The following discussion pertains to findings in patient populations in whom CEA was used specifically as a diagnostic test.

With respect to colonic adenocarcinoma and polyps, although $80 \%$ or more of patients with advanced colonic adenocarcinoma have circulating CEA (14), the CEA assay should not be used as the sole diagnostic test for suspected cancer. Positive CEA in symptomatic patients cannot be interpreted as indicating the presence of malignant growth, as various benign conditions are associated with elevated CEA levels (82). Foremost 
among these is liver disease (107); over $90 \%$ of patients with chronic liver disease and $50 \%$ of those with acute liver disease have raised plasma levels of CEA or CEA-like substances (108). There are numerous reports of elevations of CEA or CEA-like substances in a variety of conditions. However, benign conditions are rarely a cause of substantial elevations $(>10 \mathrm{ng} / \mathrm{ml})$, and such conditions do not give rise to the progressive increases in CEA levels seen in cancerous states. CEA levels are likely to be higher in symptomatic, rather than asymptomatic, colorectal cancer patients, but such patients are more likely to have advanced disease (109).

With increasing tumor burden, there is a rise in both the frequency of positive CEA assays and the absolute plasma CEA levels. Thus, the incidence of positive CEA assays may range from $20 \%$ in patients with Dukes Stage A to $90 \%$ in Dukes Stage D colon cancer. Holyoke et al. (110) demonstrated significant CEA elevations of $18 \%, 53 \%, 62 \%, 65 \%$ and $79 \%$ in patients with colon cancer of Dukes Stages A, B1, B2, C1, and C2, respectively. Similar results have been reported by Booth et al. (111) and recently by Goldberg et al. (112). Increased CEA has also been observed in fecal samples from $50 \%$ of colorectal carcinoma patients; the antigen appears as the membrane-bound form, reflecting the destruction of epithelial cells (113).

The application of monoclonal antibody (mAb) technology targeting CEA, alone or in combination with other tumor markers, has recently demonstrated high sensitivities in the diagnosis of colon adenocarcinoma. A sensitivity of $78 \%$ for Dukes Stage B and $91 \%$ for Dukes Stage C has been achieved using mAbs to the combination of CEA, CA 19-9, and TPA; Stage D disease can be diagnosed with 100\% sensitivity when mAbs to a combination of only CEA and CA 19-9 are used (114).

Adenomatous colonic polyps are the precursors of invasive cancer. Such polyps are usually not associated with elevated serum CEA levels and serum CEA levels are not presently useful for distinguishing locally invasive polyps from benign lesions $(112,115)$. The same is true of the utility of the CEA assay in distinguishing benign from early malignant lesions of the stomach and pancreas (116-119).

As alluded to earlier, sensitive radio- and enzyme-immunoassays have shown that serum CEA may be elevated in neoplastic diseases of the breast, lung, prostate, bladder and stomach as well as in various gynecological malignancies (120). As in the case of colorectal cancer, CEA measurements are not sufficient as the sole parameter for diagnosis of early breast cancer (121-132). Early diagnosis of subclinical lymph node metastases from cancer of the breast or gastrointestinal tract has recently shown promise through the use of a reverse transcriptase PCR assay detecting CEA-expressing carcinoma cells; this diagnostic modality has demonstrated a greater than two-fold increase in the incidence of positive nodes (133). In advanced breast cancer, quite interestingly, the correlation between CEA level and occurrence of metastases from the breast has been found to vary with the site of metastasis (124). Patients with bone or visceral involvement have more frequent elevations (48-100\%) and higher levels than patients with soft tissue metastases (9-52\%).

In lung cancer, CEA can also be a useful biomarker. CEA is elevated in approximately two-thirds of nonsmall cell lung cancer patients and one-third of those with small cell lung cancer (134-136). Both the frequency and levels of CEA elevation are considerably lower in patients with benign lung diseases. Determination of CEA concentration can be used as a diagnostic tool for malignant pleural effusions, in that $40-70 \%$ of the fluids from initial pleural taps give positive CEA assays (136). However, although no large randomized study has been performed to date, preliminary work has suggested limited clinical utility for serum CEA and BALF CEA in the diagnosis of lung cancer (137). The determination of CEA levels in cerebrospinal fluid, albeit less studied, seems useful in diagnosing meningeal carcinomatosis (138), while analysis of gastric juice for CEA is useful in identifying high-risk patients for gastric cancer (139). In a recent study involving 90 patients with esophageal or gastric adenocarcinoma, CEA positivity in serum (i.e., $>5$ $\mathrm{ng} / \mathrm{ml}$ ) was found to be $20 \%$ (140). Although serum CEA has not proved satisfactory as an indicator of early gastric cancer (141), elevated CEA levels have been detected in the majority of patients with advanced carcinoma of the stomach $(80,142)$. 
Although serum CEA assays have not been as useful as had been envisaged initially in the screening and diagnosis of colonic carcinoma, they play an important role in the clinical management of patients with colorectal adenocarcinomata (143), as discussed below.

\section{CEA as a Prognostic Indicator}

Considerable investigation has addressed the potential utility of CEA in determining disease prognosis in patients with colorectal and various other cancers. Preoperative serum CEA levels in diagnosed colorectal cancer are elevated in 40-70\% of patients (144-148), and have been found to correlate inversely with tumor grade and directly with pathological stage $(84,149-161)$. Thus, CEA is raised in $95 \%$ of patients with welldifferentiated tumors, while it is elevated in as few as $30 \%$ of those with poorly-differentiated adenocarcinomas $(155,162)$.

A significant inverse relationship between preoperative elevated plasma CEA levels and patient survival has been observed $(149,151,153,159,163-167)$. Despite disagreement among various investigations of the relationship between preoperative CEA and prognosis, most report that a high preoperative CEA level is indicative of a poor prognosis. This association is often as predictive of prognosis as are pathological staging and grading $(91,155,156,165,168-173)$. On the basis of these observations, the National Institutes of Health suggested in their 1981 Consensus Statement (62) that CEA determination should be used as an adjunct to staging. However, the precise preoperative CEA value that reliably discriminates high-risk from low-risk cases for postoperative recurrence is as yet unclear $(148,151,153,155,160,163,164,168)$.

CEA is also an important marker of prognosis for cancer of the breast. Preoperative CEA levels have been studied as prognostic factors in early breast cancer by many investigators. The results are variable and controversial $(81,88,91,93,125,127,128,131,132,153,160,174-191)$, but generally there is sufficient evidence that the CEA level is a prognostic indicator in patients with breast cancer $(81,132,178,183,186,190,192,193)$. In most cases, preoperatively raised CEA levels have been found to correlate with a poor prognosis, such as increased likelihood and decreased latency of tumor recurrence. By detecting a rise in plasma levels of antigen, serial postoperative CEA measurement in clinically disease-free patients appears to accurately predict the development of metastatic disease $(115,186,194)$. An elevated or rising CEA level preceded clinical recurrence by one to 31 months in some patients $(124,194,195)$.

Clinical evidence also indicates that both pre- and post-treatment CEA levels could serve as prognostic markers in cancers of the stomach (196) and lung $(197,198)$, although the evidence is not as compelling and well-documented as for cancers of the colon and the breast. Further investigations are needed to establish whether changes in patient management based upon these prognostic indicators will be of clinical benefit.

\section{CEA in Treatment Monitoring}

At the present time, treatment monitoring is certainly the most useful area for CEA testing. A rise in the blood CEA concentration in a patient after apparently successful surgical treatment for cancer has repeatedly been shown to signal a recurrence of the tumor. After apparently complete surgical resection of colorectal cancer, the blood CEA concentration, if elevated before surgery, falls to the normal range in nearly all patients (154). The fall usually occurs within one month but sometimes takes up to four months (199). If levels fail to fall to the normal range, it is likely that the resection has been incomplete or that the cancer had already metastasized. After the initial return of CEA to normal levels, it is not uncommon for transient, small elevations in serum CEA levels to occur in the absence of recurrent tumor. However, a sustained and progressive rise has repeatedly been shown to signal tumor recurrence. Although the best evidence for this phenomenon is found in colorectal cancer, similar data have been obtained in other CEA-expressing tumors. Serial CEA monitoring is currently considered the best non-invasive technique for detecting recurrent colorectal cancer $(163,200-204)$. In a study of over 300 colorectal cancer patients followed post-operatively 
with serial serum CEA determination, the observation of two consecutive elevations in the CEA level yielded a sensitivity of $84 \%$ and a specificity of $100 \%$ in the detection of recurrence, and in $72 \%$ of cases preceded all other clinical signs (205).

The debate concerning the merit of postoperative determinations of CEA values in monitoring patients with resected colon cancer continues to rage. At one extreme are those who suggest that cancer cures attributable to CEA monitoring and subsequent intervention are achieved too infrequently to justify the costs and stress that such testing may cause for patients (175). Nevertheless, numerous authorities maintain that intensive follow-up using CEA assays makes possible the identification of treatable recurrences at a relatively early stage; this latter view has been substantiated by a recent extensive meta-analysis (176). The literature provides various parameters for predicting tumor recurrence based on postoperative CEA monitoring for colorectal carcinomas $(126,153,170,199,204,206-212)$. These include both CEA levels exceeding a predetermined cut-off value and progressively rising CEA levels exceeding a specific rate of change. Various cut-off values ranging from 4 to $20 \mathrm{ng} / \mathrm{ml}$ have been suggested, depending on assay sensitivity and the patient population studied. Clinical investigations based on these parameters have, expectedly, yielded a variety of sensitivity/specificity ratios. Clearly, further controlled studies are required in order to arrive at an internationally agreed upon standard of procedure.

Nevertheless, it has been suggested recently that when CEA increases more rapidly than an average of $12.6 \%$ per month, recurrence should be strongly suspected (213). Serial CEA determinations may in this way allow initiation of anti-tumor chemotherapy, radiotherapy, or second-look surgery at an earlier stage of progression of recurrent colorectal cancer and offer a better outcome for the patient. Again, a well-controlled double-blind clinical trial will be required to determine the efficacy of this approach. In the context of a dismal overall prognosis for patients with recurrent disease after surgical resection, serum CEA determination may offer the only chance of a cure for a select group of individuals.

In addition to its use in colorectal cancer, there is general agreement that the implementation of regular and sequential assays for plasma or serum CEA provides valuable information postoperatively concerning regression or progression of cancer growth in patients receiving chemotherapy and/or radiotherapy for breast cancer, lung cancer, or meningeal carcinomatosis. In breast cancer, studies utilizing serial determinations of serum CEA and CA 15-3 in combination for the postoperative follow-up of patients with primary or recurrent disease have demonstrated sensitivities ranging between $64 \%$ and $94 \%$ in the detection of metastases $(214,215)$. In breast cancer patients who had been treated by either radical mastectomy or simple mastectomy plus local radiotherapy, the overall specificity using the combination of CEA and CA 15-3 was $99 \%$ in the detection of non-locoregional metastases (215). Interestingly, estrogen receptor (ER)-positive and progesterone receptor (PR)-positive tumors were associated with greater lead-times, higher levels of both tumor markers at the time of diagnosis of recurrence, and higher sensitivities in the early diagnosis of relapse (215), suggesting a potential for improved success of hormonal therapy via this regimen of treatment monitoring.

In addition, it has been shown that $80 \%$ of distant metastases arising in beast cancer patients followed by serial CEA and CA 15-3 in combination are detectable up to several months earlier than by standard followup (216). It is worthy of note here that, based on improved diagnostic sensitivity and specificity rates, the use of individual reference limits reflecting variations in marker levels for a given patient has recently been advocated in the detection of breast cancer recurrence, in lieu of standard thresholds for CEA and CA 15-3 (217). While the aforementioned results for the utility of serum CEA and CA 15-3 toward the early detection of metastatic breast cancer are encouraging, they must be tempered by the fact that studies to date have not adequately established whether this early detection provides clinical benefit.

As for lung cancer, the use of serial serum CEA determinations in the monitoring of patients with surgicallytreated non-small cell lung cancer revealed a sensitivity of $58 \%$ in the detection of recurrence; this figure 
increased to $88 \%$ with concomitant analysis of serum CA 125 and squamous cell carcinoma antigen (218). Serial CEA assay may also be useful in a number of other tumors that have been less well studied to date $(89,117,137,138,185,172,184,187,188,195,219-229)$. In patients with gastric or esophageal carcinoma, for example, an elevated CEA level during serial follow-up after preoperative chemotherapy has been shown to be predictive of relapse, and has demonstrated the potential for diagnosis of recurrent disease in advance of its clinical presentation (140).

Overall, the available data indicate that the assay for CEA is useful, both preoperatively and postoperatively, in the management of patients in whom the diagnosis of cancer has already been established. Assuredly, major advances in treatment of recurrent disease will further increase the clinical utility of the CEA assay.

\section{Immunohistochemical Diagnosis}

Immunoperoxidase staining of neoplastic tissue is a simple, sensitive method that is widely used in modern clinical pathology laboratories. The value of tissue CEA staining in cancer diagnosis depends greatly on the antibodies used for detection. A wealth of mAbs to CEA have been generated. They exhibit various degrees of cross-reactivity to other members of the CEA molecular family but, nevertheless, several excellent antiCEA mAbs reagents are available commercially.

Immunohistochemically, CEA has been identified in cancers of the colorectum (230-232), breast (233), lung (234) uterine cervix (235), gallbladder (236), stomach (237), pancreas (238), liver (239), prostate, urinary bladder, and uterus $(240,241)$, and in neuroendocrine tumors associated with the larynx, lung and thyroid (242).

There have been numerous attempts to compare the incidence of immunohistochemical staining for CEA with plasma CEA levels, tumor differentiation, disease stage, histologic tumor type, CEA intensity, distribution, cellular localization and clinical prognosis for various carcinomas $(118,180,187,231-237,243-249)$. A positive correlation between serum CEA concentrations and the intensity of tissue CEA staining has been reported for cancers of the colorectum $(250,251)$ breast $(252,253)$, pancreas $(243)$, as well as for gestational and nongestational choriocarcinomas (254). No correlation was observed for gastric cancer (118). Overall, the incidence of positive colorectal cancer tissue staining is similar to the frequency of elevated serum CEA levels. When differences have been found, these have indicated a higher sensitivity for tissue staining than for serum CEA levels.

Conflicting results have been published with regard to the relationship between tissue CEA staining and tumor differentiation in colorectal carcinomas, with some reports indicating no correlation $(143,246,250$, 255-257). Certainly, study design, different antibody preparations and methods of interpretation may result in apparently differing observations.

There are good reasons to regard ulcerative colitis and certain colonic adenomas as premalignant lesions (253). Immunoperoxidase staining for CEA supports the concept of a polyp-adenoma-cancer sequence (258). Studies of the localization of CEA in colonic polyps designated histopathologically as benign showed weak to moderate staining for CEA, whereas $100 \%$ of polyps that were graded as being severely dysplastic were strongly positive for CEA. These findings indicate that immunoperoxidase staining of apparently benign polyps for CEA may be of value in indicating when there is a need for close monitoring of patients with colorectal polyps. Both chronic inflammatory bowel disease and colorectal adenomas show higher tissue CEA concentrations than normal colonic mucosa, suggesting that these situations can be regarded as precancerous conditions biochemically $(249,259,260)$. Strong CEA-positivity has also been observed in chronic pancreatitis (238), cystic fibrosis (261), gallbladder hyperplasia and chronic cholecystitis (236).

That anti-CEA antibodies stain normal colon mucosa, albeit very weakly $(6,180,262-264)$, is not surprising 
since normal colon mucosal cells produce CEA in culture $(265,266)$ and CEA mRNA is actively expressed in the normal colonic mucosal cells $(17,24,29,34)$. CEA has also been demonstrated immunohistochemically in normal epithelial cells of the respiratory system (267). It has also been found in $77 \%$ of pancreatic tumors by this technology but the approach has no value in discriminating between chronic pancreatitis and pancreatic carcinoma, since a significant proportion of inflamed tissues stain positively for CEA $(238,268)$.

Immunohistochemical demonstration of CEA in breast tumors has been attempted by several groups and it is evident from these studies that CEA is present in mammary cancer tissue in the majority of cases, whereas benign lesions are virtually all negative.

Results concerning the correlation between positive tumor CEA immunohistochemistry and histologic grade, lymph node involvement, locoregional recurrence, disease-free interval and patient survival remain controversial. Nevertheless, considerable data indicate that a significant relationship exists between immunohistochemical CEA-positivity of mammary carcinomas on the one hand, and the presence of lymph node metastases, five-year survival rates and histological type on the other $(180,245,263,269)$. A nearly $90 \%$ correlation between Grade III breast cancer with lymph node metastases and this form of CEA-positivity has been found as opposed to 40-45\% CEA-positivity in Grade I and Grade II breast cancer (253). Invasive ductal carcinoma usually shows more intense tissue CEA staining as compared to tubular, cribriform, and invasive lobular carcinomas. The intensity of CEA staining is also associated with a worse prognosis. However, contrary data has also been published (270-274). In addition, no correlation has been found between tissue CEA and estrogen receptor status (274). Thus, it appears that the role of immunohistochemistry in determining the prognosis in breast cancer remains to be clarified.

CEA staining is strongly positive in gastric tumors and its distribution apparently correlates with histologic type, degree of differentiation, and tumor prognosis $(112,237,264,275)$. Staining for CEA in fine needle aspiration biopsy specimens has been reported to differentiate between primary hepatocellular carcinoma and CEA-producing metastatic cancer to the liver (239). Ninety percent of hepatocellular carcinomas show CEA staining that has a predominantly biliary canalicular pattern, while metastatic lesions demonstrate a diffuse cytoplasmic pattern, where positive. A few reports have described CEA immunostaining in small cell lung carcinoma $(234,241,276)$ but no correlation between

the degree of immunostaining and clinical parameters has been reported. The majority of cervical adenocarcinomas show positive staining for CEA, but no relation to clinical or histopathological tumor characteristics has been demonstrated $(235,277)$. With the data available, it has been suggested that the CEA staining status of tumor tissue, and the pattern of that staining, might be very helpful in determining if the tumor tissue under consideration was primary to the organ or of metastatic origin. This would be very helpful, for example, in gastrointestinal cancer metastases (CEA-positive) to the ovary (CEA-negative) and in other comparable situations $(109,167,231,232,240,278-280)$. As the impact of

CEA immunohistochemistry becomes increasingly important, it must also be underlined that CEA can easily be demonstrated, retrospectively, in routinely-fixed, paraffin-embedded sections.

\section{Radioimmunolocalization (RIL) of Cancers Using Anti-CEA Antibodies}

RIL procedures using tumor-specific antibody has the potential to differentiate between malignant and benign tissues in vivo. RIL of tumors was pioneered by Pressman and Korngold in 1953 using osteosarcomas as the target (281). In 1974, Reif (282) attempted to detect metastatic cancer in a patient with advanced colon carcinoma using radiolabeled antibody to CEA. The radiolabel did not localize to the cancer tissue. The first successful reports demonstrating specific localization of anti-CEA in xenografts of human tumors in animals were published by Goldenberg and Primus $(283,284)$ and Mach et al. (145). Subsequently, extensive studies have demonstrated the RIL of antibodies against human tumor markers in both animal models and in patients. Due to cross-reactivity of polyclonal anti-CEA antibodies with NCA and other members of the CEA family, only affinity-purified anti-CEA polyclonal antibodies and/or monoclonal antibodies having minimal or no 
cross-reactivity with normal tissue epitopes or plasma components are likely to be effective as targeting agents (285).

The pioneering work of Goldenberg et al. (286-288) and Mach et al. (289) using affinity-purified, iodinelabeled polyclonal antibodies to localize advanced neoplastic diseases in man stimulated a number of clinical studies of RIL over the past 15 years. The availability of sophisticated nuclear imaging technology and the development of high-affinity anti-tumor monoclonal antibodies has subsequently improved imaging quality.

In humans, many of the early reports of tumor imaging with labeled anti-CEA antibodies were inconsistent and rather discouraging (281-283,289-292). This was primarily due to variability in the distribution of the conjugate and free isotope between normal and tumor tissues, as well as to blood pooling in various normal tissues and organs. Residual anti-CEA antibody cross-reactivity with antigens on normal cells, either by mAbs or polyclonal antisera, might also have contributed to the problem. However, most results to date indicate that, despite the technical and biologic problems defined, primary and secondary cancers can be successfully imaged with appropriately prepared anti-CEA antibodies (86,286-288,293-315).

Studies of gastrointestinal cancers utilizing antibodies to CEA have demonstrated effective RIL of tumors in $70 \%$ to over $90 \%$ of patients. Hepatic metastases, on the other hand, appear to be much more difficult to image because of the high background uptake and the blood pool of radioactivity in normal liver tissue and relatively low uptake in the metastatic lesions, particularly with ${ }^{111}$ In. The reported sensitivities for detection of liver metastases have ranged from $0-94 \%$ in different studies, reflecting differences largely in technical ability and skill in avoiding pitfalls. To improve the uptake of antibody-bound radiolabel by hepatic metastatic lesions, intraperitoneal (302) and intra-aortic (301), rather than intravenous, injections of anti-CEA preparations have been used with some success, as has the simultaneous injection of monoclonal anti-CEA antibody in an attempt to "block" the normally high liver uptake. In the latter case, the improved scintigrams of metastatic lesions suggest that the "blocking" effect of unlabeled mAbs influences the nonspecific distribution of labeled monoclonal antibody, perhaps primarily through the reduction of liver uptake of isotope-labeled anti-CEA mAbs. This has increased the sensitivity for detecting metastases $(308,314)$.

The use of nuclear scintiscans to detect potentially operable recurrences has met with variable success depending on the site of tumor spread and the immunoconjugate used. Other potential variables include the radiolabel employed, the route of administration of the conjugate, tumor size and location, tumor vascularity, the patient population studied, the imaging technology employed, the unavoidable parameter of subjective interpretation of scans (even in blinded situations), and the type of antibody preparation used. Direct comparisons are difficult, because different techniques for imaging tumors have been employed. As in the case of animal studies, antibody fragments rather than intact immunoglobulins have been utilized with improved imaging quality $(302,303,315,316)$. It is worthy of note that although many of the nuclear scintiscan studies to date have utilized correlative data from other imaging modalities, such as X-rays, CT scans, nuclear scans and ultrasound studies, histopathological assessment of the imaged tissue has seldom been reported in the published investigations.

Several major problems have hindered the progression of RIL to routine medical use. The relatively low antibody accumulation of isotope-antibody conjugate in tumors when compared with the amount of antibody injected has resulted in less than desirable contrast between cancerous and normal tissues. In addition, high uptake by normal liver tissue when ${ }^{111}$ In-labeled antibodies are employed has limited the usefulness of such reagents and the high uptake of radiolabeled monoclonal anti-CEA by normal mesenteric lymph nodes (294) and testis (293) poses a challenge to the realization of full clinical utility. New technetium labeling kits, however, may well have a major impact on RIL, primarily due to low cost, simplicity of labeling, and lower liver uptake of the conjugates. 
single-photon emission computed tomography (SPECT) $(295,305,306)$, have been employed to increase tumor/normal tissue image contrast ratio, improving the sensitivity of detection. Further advancement may stem from a recent report on the effects of hyperthermia on tumor CEA expression, which indicates that tumor tissue warming may well increase membrane CEA expression and, thereby, have clinical implications for RIL (317). In addition, preliminary studies have demonstrated that the use of combinations of antibodies to different epitopes of CEA increases the ease of detection of tumors, presumably reflecting increased total uptake of the injected preparations (318). Alternatively, increased amounts of antibody to the same epitope may produce similar results. However, it might be postulated that attempts to saturate the circulating and tissue epitopes by administering high doses of mouse anti-CEA mAbs may evoke some allergic side effects due to foreign protein or lead to the development of anti-murine antibodies, which could inactivate or eliminate the administered antibody, precluding sequential imaging procedures. The presence of antibodies against murine immunoglobulin, as well as anti-idiotypic antibodies after injection of murine mAbs, has in fact been reported in humans (319-321), although the clinical significance of this is unclear.

Circulating CEA poses another potential problem for the RIL process. The CEA antigen shed into the circulation was shown in early studies to bind to administered anti-CEA antibodies $(319,322)$ with the possibility of antigen-antibody complex formation and the attendant possibility for development of renal and other pathologies. Fortunately, there has been no evidence to date of any such problem. Moreover, the clinical evidence described to date indicates that there is no correlation between serum CEA concentration and the quality of the image or frequency of lesion detection, while there is a direct relationship between both tumor size and tumor CEA expression and sensitivity of RIL. At present, effective imaging can be achieved for those tumors expressing membrane CEA and measuring larger than $1.5 \mathrm{~cm}$.

Recently, considerable advances have been made in the clinical utility of RIL, particularly in the contexts of colorectal and breast cancer. A European multicenter trial using a ${ }^{99 \mathrm{~m}} \mathrm{Tc}$-labeled anti-CEA monoclonal antibody for immunoscintigraphic visualization of CEA-expressing tumors showed an $80 \%$ sensitivity rate in the detection of colorectal primaries and their abdominopelvic metastases and a $90 \%$ sensitivity rate in the detection of recurrent disease (323). Importantly, in 17\% of the patients studied, this imaging modality detected cancers that had eluded standard diagnostic methods, and in a considerable number of patients yielded additional clinically-relevant information. These favorable results have been corroborated by further work in which immunoscintigraphy of patients with colorectal cancer using a radiolabeled anti-CEA mAb demonstrated an overall sensitivity of $93 \%$ in tumor detection (324). In addition, in a recent study involving nine patients with metastatic colorectal cancer, ${ }^{123}$ I-labeled anti-CEA single-chain variable fragment ( $\mathrm{scFv}$ ) antibody imaging with SPECT not only demonstrated the ability to localize all tumor deposits detected by conventional methods, but also those liver metastases only confirmed by CT portography (325). Furthermore, a study of the use of ${ }^{99} \mathrm{Tc}$-labeled anti-CEA antibody immunoscintigraphy in combination with CT to define the extent of tumor recurrence or metastasis in colorectal cancer patients has demonstrated an increase in the identification of resectable patients by $40 \%$, and of non-resectable patients by $100 \%$, as compared to use of CT alone (326).

As for breast carcinoma, one series of immunolymphoscintigraphy for metastases showed remarkable success, with a sensitivity of $90 \%$ and a specificity of $88 \%$ (327). In addition, the aforementioned ${ }^{99} \mathrm{Tc}-$ labeled anti-CEA antibody imaging modality, originally developed for colorectal cancer (326), has quite recently achieved a very high specificity in the detection of breast cancer in patients with indeterminate mammographic lesions, offering the potential for a substantial decrease in the number of such patients undergoing surgical biopsy for subsequently histopathologically-proven benign disease (328).

The future promises further success in tumor imaging through better comprehension of the pharmacokinetics of radiolabeled antibodies and a clearer Understanding of the immunobiology of CEA-producing tumors. 
Given that adenocarcinoma of the colorectum is the second most prevalent cancer in the United States (329), and that relatively early diagnosis presently results in surgical cures in about $50 \%$ of patients, the potential impact of the development of effective adjuvant therapies is far-reaching. Yet, current adjuvant chemotherapy is not very successful in those patients whose tumors have been resected but have a high risk for recurrence (i.e., Dukes Stages B2 and C tumors).

The ability to detect tumors by RIL raises the exciting possibility of treating such tumors by targeting with the same technology. Passive immunotherapy for the treatment of human CEA-producing cancers may be performed in a number of ways using anti-CEA antibodies as "homing devices" to target, with improved specificity, the delivery of cytotoxic radionuclides or chemotherapeutic agents, toxins, or pro-drugs to tumor cells. Active immunization has also been attempted in model systems with purified CEA-producing autologous cancer cells, anti-CEA anti-idiotypic antibodies, and photodynamic therapy (for review, see 330).

Another intriguing approach to the treatment of CEA-producing tumors has developed through the incorporation of the recombinant CEA gene or gene segments into an appropriate vector, such as vaccinia virus. This construct, both alone and in combination with other gene products to stimulate an immune response, has been shown to enhance cell-mediated anti-CEA immunity in both animal and human studies (331), and is currently being analyzed in clinical trials. An additional vaccine prototype has shown a protective effect against tumor challenge in mice, and has recently been modified for human clinical trials (332). Yet another prospect for treatment involves the gene therapy approach. Xenografting of CEAexpressing clones into which a chimeric gene for CEA and CD-145 has been introduced has recently yielded antitumor effects in mice after treatment with 5-fluorocytosine, illustrating the potential for specific gene therapy of CEA-positive tumors (333).

\section{ACKNOWLEDGMENTS}

The first author is indebted to the numerous colleagues with whom he has worked over the years and who appear as co-authors in some of the papers cited in this article. Special appreciation is due to: Sam Freedman, for seeing the promise in some marginal thoughts; Joe Shuster, for being an unfailing source of optimism, ideas, and friendship; John Krupey, for his unparalleled skill as a "seat-of-the-pants" chemist; Abe Fuks, for bringing monoclonal antibody technology to bear on the studies; and Cliff Stanners and his colleagues at the McGill Cancer Centre, such as Nicole Beauchemin and Sarita Benchimol, for taking the work to its present generation of biological excellence.

Internationally, from among hundreds of colleagues and friends, the following individuals must be distinguished: Sabine von Kleist, who, although an ocean away, was there from the beginning and has remained a steadfast friend and colleague through both difficult and good times; Sten Hammerström, for both his good science and good humor; and the late Charlie Todd, simply for believing.

Much gratitude is deserved by Cliff and Sarita for reviewing the basic science aspects of this manuscript, to Hanna Sikorska for doing so much of the leg-work on the clinical status of the CEA phenomenon, and to the first author's Administrative Secretary, Nicole Brown, for all of her help with the manuscript.

Finally, the first author expresses heartfelt thanks to his wife, Evelyn, for a yeoman effort with the bibliography and, above all, for her unfailing support and tolerance for over 35 years.

From among numerous influential individuals, the second author wishes to express deep gratitude to his father, for cultivating, through many years of unparalleled contribution to the CEA field, his son's interest in cancer research, and to Dr. Gold, for his unyielding enthusiasm as devoted teacher and friend. 


\section{REFERENCES}

1. Kierkegaard S. Journals and Papers, (vol. 1 transl.). Hong HV, Hong EH, Malantschuk G, eds. Bloomington, IN: University of Indiana Press.; 1969. (Originally published 1843).

2. Kuhn TS. The Structure of Scientific Revolutions, 2nd ed.; 1970: 625.

3. Billingham RE, Brent L, Medawar PB. Actively acquired tolerance of foreign cells. Nature 172: 603-606; 1953.

4. Hauschka TS. Immunologic aspects of cancer: review. Cancer Research 12: 615; 1952.

5. Oettgen HF, Hellström KE. Tumor Immunology. In: Holland JF, Frei E, eds. Cancer Medicine. Philadelphia: Lea and Feibiger; 1973: 951.

6. Gold P, Freedman SO. Demonstration of tumor-specific antigens in human colonic carcinomata by immunological tolerance and absorption techniques. Journal of Experimental Medicine 121: 439; 1965.

7. Gold P, Freedman SO. Specific carcinoembyronic antigens of the human digestive system. Journal of Experimental Medicine 122: 467; 1965.

8. Krupey J, Gold P, Freedman SO. Purification and characterization of carcinoembryonic antigens of the human digestive system. Nature 215(96): 67-68; 1967.

9. Krupey J, Gold P, Freedman SO. Physicochemical studies of the carcinoembryonic antigens of the human digestive system. Journal of Experimental Medicine 128(3): 387-398; 1968.

10. Madjic O. Cluster report: CD66. In: Knapp W, et al., eds. Leucocyte Typing IV. Oxford, England: Oxford University Press; 1989: 838.

11. Gold P, Krupey J, Ansari H. Position of the carcinoembryonic antigen of the human digestive system in ultrastructure of tumor cell surface. Journal of the National Cancer Institute 45(2): 219-225; 1970.

12. Rosenthal KL. Palmer JL. Harris JA, et al. Antibody-induced redistribution of CEA on the cell surface: utilization in separation of CEA and isoantigen A. Journal of Immunology 115(4):1049-1053; 1975.

13. Pignatelli M, Durbin H, Bodmer WF. Carcinoembryonic antigen functions as an accessory adhesion molecule mediating colon epithelial cell-collagen interactions. Proceedings of the National Academy of Sciences (USA) 87(4): 1541-1545; 1990.

14. Thomson DM, Krupey J, Freedman SO, et al. The radioimmunoassay of circulating carcinoembryonic antigen of the human digestive system. Proceedings of the National Academy of Sciences (USA) 64(1): 161$167 ; 1969$.

15. Terry WD, Henkart PA, Coligan JE, et al. Carcinoembryonic antigen: characterization and clinical applications. Transplantation Reviews 20(0): 100-129; 1974.

16. Benchimol S, Fuks A, Jothy S, et al. Carcinoembryonic antigen, a human tumor marker, functions as an intercellular adhesion molecule Cell 57(2): 327-334; 1989.

17. Oikawa S, Nakazato H, Kosaki G. Primary structure of human carcinoembryonic antigen (CEA) deduced from cDNA sequence. Biochemical \& Biophysical Research Communications 142(2): 511-518; 1987. 
18. Hefta SA, Hefta LJ, Lee TD, et al. Carcinoembryonic antigen is anchored to membranes by covalent attachment to a glycosylphosphatidylinositol moiety: identification of the ethanolamine linkage site. Proceedings of the National Academy of Sciences (USA) 85(13): 4648-4652; 1988.

19. Slayter HS, Coligan JE. Electron microscopy and physical characterization of the carcinoembryonic antigen. Biochemistry 14(11): 2323-2330; 1975.

20. Thompson J, Zimmermann W, Osthus-Bugat P, et al. Long-range chromosomal mapping of the carcinoembryonic antigen (CEA) gene family cluster. Genomics 12(4): 761-772; 1992.

21. Sikorska H, Massie C, Gold P. Carcinoembryonic antigen and its utility in the diagnosis of colonic adenocarcinoma. In: Cinader B, Miller RG, eds. Progress in Immunology VI (Sixth International Congress of Immunolgy). Toronto: Academic Press, Inc.; 1986: 723.

22. Shively JE, Beatty JD. CEA-related antigens: molecular biology and clinical significance. Critical Reviews in Oncology-Hematology 2(4): 355-399; 1985.

23. Paxton RJ, Mooser G, Pande H, et al. Sequence analysis of carcinoembryonic antigen: identification of glycosylation sites and homology with the immunoglobulin supergene family. Proceedings of the National Academy of Sciences (USA) 84(4): 920-924; 1987.

24. Zimmermann W, Ortlieb B, Friedrich R, et al. Isolation and characterization of cDNA clones encoding the human carcinoembryonic antigen reveal a highly conserved repeating structure. Proceedings of the National Academy of Sciences (USA) 84(9): 2960-2964; 1987.

25. Kamarck ME, Elting JJ, Hart JT, et al. Carcinoembryonic antigen family: expression in a mouse L-cell transfectant and characterization of a partial cDNA in bacteriophage lambda gt11. Proceedings of the National Academy of Sciences (USA) 84(15): 5350-5354; 1987.

26. Beauchemin N, Benchimol S, Cournoyer D, et al. Isolation and characterization of full-length functional cDNA clones for human carcinoembryonic antigen. Molecular \& Cellular Biology 7(9): 3221-3230; 1987.

27. Neumaier M, Zimmermann W, Shively L, et al. Characterization of a cDNA clone for the nonspecific cross-reacting antigen (NCA) and a comparison of NCA and carcinoembryonic antigen. Journal of Biological Chemistry 263(7): 3202-3207; 1988.

28. Tawaragi Y, Oikawa S, Matsuoka Y, et al. Primary structure of nonspecific crossreacting antigen (NCA), a member of carcinoembryonic antigen (CEA) gene family, deduced from cDNA sequence. Biochemical \& Biophysical Research Communications 150(1): 89-96; 1988.

29. Cournoyer D, Beauchemin N, Boucher D, et al. Transcription of genes of the carcinoembryonic antigen family in malignant and nonmalignant human tissues. Cancer Research 48(11): 3153-3157; 1988.

30. Streydio C, Lacka K, Swillens S, et al. The human pregnancy-specific beta 1-glycoprotein (PS beta G) and the carcinoembryonic antigen (CEA)-related proteins are members of the same multigene family. Biochemical \& Biophysical Research Communications 154(1): 130-137; 1988.

31. Khan WN, Hammarstrom S. Carcinoembryonic antigen gene family: molecular cloning of cDNA for a PS beta G/FL-NCA glycoprotein with a novel domain arrangement. Biochemical \& Biophysical Research Communications 161(2): 525-535; 1989.

32. Khan WN, Hammarstrom S. Identification of a new carcinoembryonic antigen (CEA) family member in 
human fetal liver--cloning and sequence determination of pregnancy-specific glycoprotein 7. Biochemical \& Biophysical Research Communications 168(1): 214-225; 1990.

33. Khan WN, Osterman A, Hammarstrom S. Molecular cloning and expression of cDNA for a carcinoembryonic antigen-related fetal liver glycoprotein. Proceedings of the National Academy of Sciences (USA) 86(9): 3332-3336; 1989.

34. Zimmermann W, Weber B, Ortlieb B, et al. Chromosomal localization of the carcinoembryonic antigen gene family and differential expression in various tumors. Cancer Research 48(9): 2550-2554; 1988.

35. Thompson JA, Mauch EM, Chen FS, et al. Analysis of the size of the carcinoembryonic antigen (CEA) gene family: isolation and sequencing of N-terminal domain exons. Biochemical \& Biophysical Research Communications 158(3): 996-1004; 1989.

36. Thompson J, Koumari R, Wagner K, et al. The human pregnancy-specific glycoprotein genes are tightly linked on the long arm of chromosome 19 and are coordinately expressed. Biochemical \& Biophysical Research Communications 167(2): 848-859; 1990. Erratum published

37. Khan WN, Teglund S, Bremer K, et al. The pregnancy-specific glycoprotein family of the immunoglobulin superfamily: identification of new members and estimation of family size. Genomics 12(4): 780-787; 1992.

38. Thompson J, Zimmermann W. The carcinoembryonic antigen gene family: structure, expression and evolution. Tumour Biology 9(2-3): 63-83; 1988.

39. Oikawa S, Imajo S, Noguchi T, et al. The carcinoembryonic antigen (CEA) contains multiple immunoglobulin-like domains. Biochemical \& Biophysical Research Communications 144(2): 634-642; 1987.

40. Barnett TR, Kretschmer A, Austen DA, et al. Carcinoembryonic antigens: alternative splicing accounts for the multiple mRNAs that code for novel members of the carcinoembryonic antigen family. Journal of Cell Biology 108(2): 267-276; 1989.

41. Neumaier M, Paululat S, Chan A, et al. Biliary glycoprotein, a potential human cell adhesion molecule, is down-regulated in colorectal carcinomas. Proceedings of the National Academy of Sciences (USA) 90(22): 10744-10748; 1993.

42. Rosenberg M, Nedellec P, Jothy S, et al. The expression of mouse biliary glycoprotein, a carcinoembryonic antigen-related gene, is down-regulated in malignant mouse tissues. Cancer Research 53(20): 4938-4945; 1993.

43. Cheung PH, Luo W, Qiu Y, et al. Structure and function of C-CAM1. The first immunoglobulin domain is required for intercellular adhesion. Journal of Biological Chemistry 268(32): 24303-24310; 1993.

44. Rojas M, DeMarte L, Screaton RA, et al. Radical differences in functions of closely related members of the human carcinoembryonic antigen gene family. Cell Growth \& Differentiation 7(5): 655-662; 1996.

45. Stanners CP, Rojas M, Zhou H, et al. The CEA family: a system in transitional evolution?. International Journal of Biological Markers 7(3): 137-142; 1992.

46. Benchimol S, Fuks A, Jothy S, et al. Carcinoembryonic antigen, a human tumor marker, functions as an intercellular adhesion molecule. Cell 57(2): 327-334; 1989. 
47. Takeichi M. Cadherins: a molecular family important in selective cell-cell adhesion. Annual Review of Biochemistry 59: 237-252; 1990.

48. Rojas M, Fuks A, Stanners CP. Biliary glycoprotein, a member of the immunoglobulin supergene family, functions in vitro as a $\mathrm{Ca} 2(+)$-dependent intercellular adhesion molecule. Cell Growth \& Differentiation 1(11): 527-533; 1990.

49. Beauchemin N, Turbide C, Huang JQ, et al. Studies on the function of carcinoembryonic antigen. In: Yachi A, Shively JE, eds. The Carinoembryonic Gene Family. New York: Elsevier; 1989: 49.

50. von Kleist S, Migule I, Halla B. Possible function of CEA as cell-contact inhibitory molecule. Anticancer Research 15(5B): 1889-1894; 1995.

51. Jothy S, Yuan SY, Shirota K. Transcription of carcinoembryonic antigen in normal colon and colon carcinoma. In situ hybridization study and implication for a new in vivo functional model. American Journal of Pathology 143(1): 250-257; 1993.

52. Hostetter RB, Campbell DE, Chi KF, et al. Carcinoembryonic antigen enhances metastatic potential of human colorectal carcinoma. Archives of Surgery 125(3): 300-304; 1990.

53. Jessup JM. Tumor markers: prognostic and therapeutic implication. In Wanebo HJ, ed. Colorectal Cancer. Mosby:

St. Louis; 1993.

54. Yeatman TJ, Duan C, Mao W, et al. Augmentation of carcinoembryonic antigen release from intact, viable tumor cells by a factor in human serum. Annals of Surgical Oncology 2(4): 336-342; 1995.

55. Zhou H, Fuks A, Alcaraz G, et al. Homophilic adhesion between Ig superfamily carcinoembryonic antigen molecules involves double reciprocal bonds. Journal of Cell Biology 122(4): 951-960; 1993.

56. Eidelman FJ, Fuks A, DeMarte L, et al. Human carcinoembryonic antigen, an intercellular adhesion molecule, blocks fusion and differentiation of rat myoblasts. Journal of Cell Biology 123(2): 467-475; 1993.

57. Jothy S, Slesak B, Harlozinska A, et al. Field effect of human colon carcinoma on normal mucosa: relevance of carcinoembryonic antigen expression. Tumour Biology 17(1): 58-64; 1996.

58. Bence-Jones H. On a new substance occurring in the urine of a patient with molligies ossium. Philosophical Transactions 138: 55-62; 1848.

59. Southam CM. Areas of relationship between immunology and clinical oncology. American Journal of Clinical Pathology 62(2): 224-242; 1974.

60. Gold P. Cancer immunology. In: Freedman SO, Gold P, eds. Clinical Immunology, 2nd ed. New York: Harper \& Row;

1976: 420 .

61. Proceedings of the First International Conference on the Clinical Uses of Carcinoembryonic Antigen. Cancer 42(3 Suppl): 1397-1659; 1978.

62. Goldenberg DM, Neville AM, Carter AC. CEA (carcinoembryonic antigen): its role as a marker in the management of cancer. Journal of Cancer Research \& Clinical Oncology 101(3): 239-242; 1981. 
63. Goodyear MDE, Sutherland DJ, Malkin A, et al. Prognostic value of postoperative levels of carcinoembryonic antigen (CEA) for recurrence and survival in primary breast cancer. Reviews on Endocrine-Releated Cancer 14: 149-153; 1984.

64. Mayer RJ. Gastrointestinal cancer. In: Mayer RJ, Dale DC, eds. Scientific American Medicine, vol. 12. New York: Scientific American; 1996.

65. Garrett PE, Kurtz SR. Clinical utility of oncofetal proteins and hormones as tumor markers. Medical Clinics of North America 70(6): 1295-1306; 1986.

66. Lo Gerfo P, Herter FP, Braun J, et al. Tumor associated antigen with pulmonary neoplasms. Annals of Surgery 175(4): 495-500; 1972.

67. Delwiche R, Zamcheck N, Marcon N, et al. Carcinoembryonic antigen in pancreatitis. Cancer 31(2): 328$330 ; 1973$.

68. Pusztaszeri G, Mach J-P. Carcinoembryonic antigen (CEA) in non-digestive cancerous and normal tissues. Immunochemistry 10(3):197-204; 1973.

69. Loewenstein MS, Zamcheck N. Carcinoembryonic antigen (CEA) levels in benign gastrointestinal disease states. Cancer 42(3 Suppl): 1412-1418; 1978.

70. Chu TM, Lavin P, Day J, et al. Carcino-embryonic antigen: prognosis and monitoring of cancer. In: Lehmann FG, ed. Carcinoembryonic Proteins, vol. I. Amsterdam: Elsevier/

North-Holland;1979:55-64.

71. Endo Y, Fujino M, Kodama T, et al. Carcinoembryonic antigen in benign liver diseases. In: Lehmann FG, ed. Carcinoembryonic Proteins, vol I. Amsterdam: Elsevier/

North-Holland; 1979: 91-96.

72. Wittekind C, Von Kleist S, Sandritter W. CEA positivity in tissue and sera of patients with benign breast lesions. Oncodevelopmental Biology \& Medicine 2(6): 381-390; 1981.

73. Stockley RA, Shaw J, Whitfield AG, et al. Effect of cigarette smoking, pulmonary inflammation, and lung disease on concentrations of carcinoembryonic antigen in serum and secretions. Thorax 41(1): 17-24; 1986.

74. Herbeth B, Bagrel A. A study of factors influencing plasma CEA levels in an unselected population. Oncodevelopmental Biology \& Medicine 1(4-5): 191-198; 1980.

75. Tabor E, Gerety RJ, Needy CF, et al. Carcinoembryonic antigen levels in asymptomatic adolescents. European Journal of Cancer 17(2): 257-258; 1981.

76. Stevens DP, Mackay IR. Increased carcinoembryonic antigens in heavy smokers. Lancet 2(840): 1238$1239 ; 1973$.

77. Beaudonnet A, Gounon G, Pichot J, et al. Sex- and age-related influences on carcinoembryonic antigen in blood. Clinical Chemistry 27(5): 771; 1981.

78. Berardi RS, Ruiz R, Becknell WE Jr, et al. Does advance age limit the usefulness of CEA assays? Geriatrics 32(1): 86-88; 1977.

79. Touitou Y, Proust J, Klinger E, et al. Cumulative effects of age and pathology on plasma 
carcinoembryonic antigen in an unselected elderly population. European Journal of Cancer \& Clinical Oncology 20(3): 369-374; 1984.

80. Haines AP, Levin AG, Fritsche HA. Ethnic-group differences in serum levels of carcinoembryonic antigen. Lancet 2(8149): 969; 1979.

81. Fletcher RH. Carcinoembryonic antigen. Annals of Internal Medicine 104(1): 66-73; 1986.

82. Vest SL, Roche JK. Carcinoembryonic antigen: physician attitudes, patterns of use, and impact upon patient care. Digestive Diseases \& Sciences 27(4): 289-296; 1982.

83. Williams RR, McIntire KR, Waldmann TA, et al. Tumor-associated antigen levels (carcinoembryonic antigen, human chorionic gonadotropin, and alpha-fetoprotein) antedating the diagnosis of cancer in the Framingham study. Journal of the National Cancer Institute 58(6): 1547-1551; 1977.

84. Wanebo HJ, Rao B, Pinsky CM, et al. Preoperative carcinoembryonic antigen level as a prognostic indicator in colorectal cancer. New England Journal of Medicine 299(9): 448-451; 1978.

85. Goldenberg DM, Neville M, Carter AC, et al. Carcinoembryonic antigen: its role as a marker in the management of cancer: an NIH consensus development statement. Annals of Internal Medicine 94(3): 407$409 ; 1981$.

86. Sikorska H.M, Fuks A, Gold P. Clinical applications of carcinoembryonic antigens. In: Ballesta AM, Torre GC, Bombardieri E, et al., eds. Updating on Tumor Markers in Tissues and in Biological Fluids. Basic Aspects and Clinical Applications. Torino, Italy: Edizioni Minerva Medica S.P.A; 1993: 217.

87. Keavins JV, Cho YT, Pampier R. Clinical applications of carcinoembryonic antigen (CEA) and tissue polypeptide antigen (TGA). Bulletin of Molecular Biology in Medicine 10: 25-31; 1985.

88. De Jong-Bakker M, Hart AA, Persijn JP, et al. Prognostic significance of CEA in breast cancer: a statistical study. European Journal of Cancer \& Clinical Oncology 17(12): 1307-1313; 1981.

89. Falkson HC, Falkson G, Portugal MA, et al. Carcinoembryonic antigen as a marker in patients with breast cancer receiving postsurgical adjuvant chemotherapy. Cancer 49(9): 1859-1865; 1982.

90. Laurence DJ, Stevens U, Bettelheim R, et al. Role of plasma carcinoembryonic antigen in diagnosis of gastrointestinal, mammary, and bronchial carcinoma. British Medical Journal 3(827): 605-609; 1972.

91. Steward AM, Nixon D, Zamcheck N, et al. Carcinoembryonic antigen in breast cancer patients: serum levels and disease progress. Cancer 33(5): 1246-1252; 1974.

92. Tormey DC, Waalkes TP, Ahmann D, et al. Biological markers in breast carcinoma. I. Incidence of abnormalities of CEA, HCG, three polyamines, and three minor nucleosides. Cancer 35(4):1095-1100; 1975.

93. Tormey DC, Waalkes TP, Snyder JJ, et al. Biological markers in breast carcinoma. III. Clinical correlations with carcinoembryonic antigen. Cancer 39(6): 2397-2404; 1977.

94. Zamcheck N, Moore TL, Dhar P, et al. Kupchik H. Immunologic diagnosis and prognosis of human digestive-tract cancer: carcinoembryonic antigens. New England Journal of Medicine 286(2): 83-86; 1972.

95. Ona FV, Zamcheck N, Dhar P, et al. Carcinoembryonic antigen (CEA) in the diagnosis of pancreatic cancer. Cancer 31(2): 324-327; 1973. 
96. Fitzgerald PJ, Fortner JG, Watson RC, et al. The value of diagnostic aids in detecting pancreas cancer. Cancer 41(3): 868-879; 1978.

97. Kalser MH, Barkin JS, Redlhammer D, et al. Circulating carcinoembryonic antigen in pancreatic carcinoma. Cancer 42(3 Suppl): 1468-1471; 1978.

98. The diagnostic value of plasma carcinoembryonic antigen (CEA) in pancreatic disease. Medical Research Council Tumour Products Committee: Clinical Subgroup. British Journal of Cancer 41(6): 976-9; 1980.

99. Podolsky DK, McPhee MS, Alpert E, et al. Galactosyltransferase isoenzyme II in the detection of pancreatic cancer: comparison with radiologic, endoscopic, and serologic tests. New England Journal of Medicine 304(22): 1313-8; 1981.

100. Begent RH. The value of carcinoembryonic antigen measurement in clinical practice. Annals of Clinical Biochemistry 21 ( Pt 4): 231-238; 1984.

101. Tsutsumi Y, Nagura H, Watanabe K, et al. Immunohistochemical observations of carcinoembryonic antigen (CEA) and CEA-related substances in normal and neoplastic pancreas. Pitfalls and caveats in CEA immunohistochemistry. American Journal of Clinical Pathology 82(5): 535-542; 1984.

102. Del Favero G, Fabris C, Panucci A, et al. Carbohydrate antigen 19-9 (CA 19-9) and carcinoembryonic antigen (CEA) in pancreatic cancer. Role of age and liver dysfunction. Bulletin du Cancer 73(3): 251-255; 1986.

103. Lokich JJ. Plasma CEA levels in small cell lung cancer. Correlation with stage, distribution of metastases, and survival. Cancer 50(10): 2154-2156; 1982.

104. Gold P, Freedman SO, Shuster J, et al. Carcinoembryonic antigen--historical perspective, experimental data. In: Herberman RB, McIntire KR, eds. Immunodiagnosis of Cancer. New York: Dekker; 1979, pt. 1: $147-164$.

105. Persijn JP. Carcino-embryonic antigen 1970-1980. Netherlands Journal of Medicine 23(1) :1-3; 1980.

106. te Velde ER, Persijn JP, Ballieux RE, et al. Carcinoembryonic antigen serum levels in patients with squamous cell carcinoma of the uterine cervix: clinical significance. Cancer 49(9): 1866-1873; 1982.

107. Loewenstein MS, Zamcheck N. Carcinoembryonic antigen and the liver. Gastroenterology 72(1): 161$166 ; 1977$.

108. Bullen AW, Losowsky MS, Carter S, et al. Diagnostic usefulness of plasma carcinoembryonic antigen levels in acute and chronic liver disease. Gastroenterology 73(4 Pt 1): 673-678; 1977.

109. Scully RE. Tumors of the ovary and maldeveloped gonads. Hartman Armed Forces Institute of Pathology, Atlas of Tumor Pathology, 2nd series. Washington, D.C.: Castle House Publications; 1978.

110. Holyoke ED, Chu TM, Murphy GP. CEA as a monitor of gastrointestinal malignancy. Cancer 35(3): $830-836 ; 1975$.

111. Booth SN, Jamieson GC, King JP et al. Carcinoembryonic antigen in management of colorectal carcinoma. British Medical Journal 4(5938): 183-187; 1974.

112. Goldberg EM, Simunovic LM, Drake SL, et al. Comparison of serum CA 19-9 and CEA levels in a 
population at high risk for colorectal cancer. Hybridoma 8(5): 569-575; 1989.

113. Sugano K, Ohkura H, Hirohashi S, et al. Detection of increased fecal carcinoembryonic antigen and its characterization as a membrane-bound form in colorectal carcinoma and other gastrointestinal disorders. Japanese Journal of Cancer Research 80(12): 1156-1160; 1989.

114. Alvarez JA, Marin J, Jover JM et al. Sensitivity of monoclonal antibodies to carcinoembryonic antigen, tissue polypeptide antigen, alpha-fetoprotein, carbohydrate antigen 50, and carbohydrate antigen 19-9 in the diagnosis of colorectal adenocarcinoma. Diseases of the Colon \& Rectum 38(5): 535-542; 1995.

115. Fuks A, Shuster J, Gold P. Theoretical and practical considerations of the utility of the radioimmunoassay for carcineombryonic antigen (CEA) in clinical medicine. In:

Sells S, ed. Cancer Markers. Clifton, NJ: Humana Press; 1980: 315-327.

116. Holyoke ED, Douglass HO Jr, Goldrosen MH, et al. Tumor markers in pancreatic cancer. Seminars in Oncology 6(3): 347-356; 1979.

117. Zamcheck N, Martin EW et al. Factors controlling the circulating CEA levels in pancreatic cancer: some clinical correlations. Cancer 47(6 Suppl): 1620-1630; 1981.

118. Castelli M, Guadagni S, Bagnato A, et al. Evaluation of carcinoembryonic antigen levels in gastric juice, stomach mucosa and plasma in high-risk and gastric cancer patients. Oncology 43(3): 149-153; 1986.

119. Del Favero G, Fabris C, Plebani M, et al. CA 19-9 and carcinoembryonic antigen in pancreatic cancer diagnosis. Cancer 57(8): 1576-1579; 1986.

120. Cooper MJ, Mackie CR, Skinner DB, et al. A reappraisal of the value of carcinoembryonic antigen in the management of patients with various neoplasms. British Journal of Surgery 66(2): 120-123; 1979.

121. Concannon JP, Dalbow MH, Frich JC Jr. Carcinoembryonic antigen (CEA) plasma levels in untreated cancer patients and patients with metastatic disease. Radiology 108(1): 191-193; 1973.

122. Meeker WR Jr, Kashmiri R, Hunter L et al. Clinical evaluation of carcinoembryonic antigen test. Archives of Surgery 107(2): 266-274; 1973.

123. Borthwick NM, Wilson DW, Bell PA. Carcinoembryonic antigen (CEA) in patients with breast cancer. European Journal of Cancer 13(2): 17117-6; 1977.

124. Baylin SB, Weisburger WR, Eggleston JC et al. Variable content of histaminase, L-dopa decarboxylase and calcitonin in small-cell carcinoma of the lung. Biologic and clinical implications. New England Journal of Medicine 299(3): 105-110; 1978.

125. Haagensen DE Jr, Kister SJ, Vandevoorde JP et al. Evaluation of carcinoembryonic antigen as a plasma monitor for human breast carcinoma. Cancer 42(3 Suppl): 1512-1519; 1978.

126. Varnavides LA, O'Higgins NJ, Clark CG. Carcinoembryonic antigen (CEA) in mammary disease: a clinical evaluation. Clinical Oncology 4(4): 329-337; 1978.

127. Rimsten A, Adami HO, Wahren B, et al. Carcinoembryonic antigen in serum of unselected breast-cancer patients and of non-hospitalized controls. British Journal of Cancer 39(2): 109-115; 1979.

128. Breslin BK, Healy JB. The CEA test in breast cancer. Irish Medical Journal 74(7): 203-204; 1981. 
129. Doyle PJ, Nicholson RI, Groome GV, et al. Carcinoembryonic antigen (CEA): its role as a tumour marker in breast cancer. Clinical Oncology 7(1):53-8; 1981.

130. Waalkes TP, Enterline JP, Shaper JH, et al. Biological markers for breast carcinoma. Cancer 53(3 Suppl): 644-651; 1984.

131. Wang DY, Knyba RE, Bulbrook RD, et al. Serum carcinoembryonic antigen in the diagnosis and prognosis of women with breast cancer. European Journal of Cancer \& Clinical Oncology 20(1): 25-31; 1984.

132. Myers RE, Sutherland DJ, Meakin JW, et al. Carcinoembryonic antigen in breast cancer. Cancer $42(3$ Suppl): 1520-1526; 1978.

133. Mori M, Mimori K, Inoue H, et al. Detection of cancer micrometastases in lymph nodes by reverse transcriptase-polymerase chain reaction. Cancer Research 55(15): 3417-3420; 1995.

134. Waalkes TP, Abeloff MD, Woo KB, et al. Carcinoembryonic antigen for monitoring patients with small cell carcinoma lof the lung during treatment. Cancer Research 40(12): 4420-4427; 1980.

135. Goslin RH, O'Brien MJ, Skarin AT, et al. Immunocytochemical staining for CEA in small cell carcinoma of lung predicts clinical usefulness of the plasma assay. Cancer 52(2): 301-306; 1983.

136. Sculier JP, Body JJ, Jacobowitz D, et al. Fruhling J. Value of CEA determination in biological fluids and tissues. European Journal of Cancer \& Clinical Oncology 23(8): 1091-1093; 1987.

137. Sanguinetti CM, Riccioni G, Marchesani F, et al. Bronchoalveolar lavage fluid level of carcinoembryonic antigen in the diagnosis of peripheral lung cancer. Monaldi Archives for Chest Disease 50(3): 177-182; 1995.

138. Yap BS, Yap HY, Fritsche HA, et al. CSF carcinoembryonic antigen in meningeal carcinomatosis from breast cancer. JAMA 244(14): 1601-1603; 1980.

139. Tatsuta M, Iishi H, Yamamura $\mathrm{H}$, et al. Value of gastric juice carcinoembryonic antigen in identifying high-risk patients for gastric cancer. Oncology 45(1): 30-4; 1988.

140. Kim YH, Ajani JA, Ota DM, et al. Value of serial carcinoembryonic antigen levels in patients with resectable adenocarcinoma of the esophagus and stomach. Cancer 75(2): 451-456; 1995.

141. Ellis DJ, Speirs C, Kingston RD, et al. Carcinoembryonic antigen levels in advanced gastric carcinoma. Cancer 42(2): 623-625; 1978.

142. Ditrich C, Jakesz R, Havelec L, et al. Carcinoembryonic antigen (CEA) plasma level determination in the management of gastric cancer patients. In: Nieburys HE, Holzner JH, Valli VE, eds. Tumor markers in Cancer Control. New York: Alan Liss; 1985: 181.

143. Zamcheck N. The expanding field of colorectal cancer markers: CEA, the prototype. Cancer Bulletin 33: $141-151 ; 1981$.

144. Mach JP, Jaeger P, Bertholet MM et al. Detection of recurrence of large-bowel carcinoma by radioimmunoassay of circulating carcinoembryonic antigen (C.E.A.). Lancet 2(7880): 535-540, 1974.

145. Mach JP, Carrel S, Merenda C et al. Sordat B. In vivo localisation of radiolabelled antibodies to 
carcinoembryonic antigen in human colon carcinoma grafted into nude mice. Nature 248(450): 704-706; 1974.

146. Martin EW Jr, Kibbey WE, DiVecchia L, et al. Carcinoembryonic antigen: clinical and historical aspects. Cancer 37(1): 62-81; 1976.

147. Tomoda H, Furusawa M. The usefulness and limitations of CEA assay in the management of colorectal cancer. Japanese Journal of Surgery 11(1): 33-8; 1981.

148. Lunde OC, Havig O. Clinical significance of carcinoembryonic antigen (CEA) in patients with adenocarcinoma in colon and rectum. Acta Chirurgica Scandinavica 148(2): 189-193; 1982.

149. Lo Gerfo P, Herter FP. Carcinoembryonic antigen and prognosis in patients with colon cancer. Annals of Surgery 181(1): 81-84; 1975.

150. Zamcheck N, Doos WG, Prudente R, et al. Prognostic factors in colon carcinoma: correlation of serum carcinoembryonic antigen level and tumor histopathology. Human Pathology 6(1): 31-45; 1975.

151. Jubert AV, Talbott TM, Maycroft TM. Characteristics of adenocarcinomas of the colorectum with low levels of preoperative plasma carcinoembryonic antigen (CEA). Cancer 42(2): 635-639; 1978.

152. Zamcheck N. CEA in diagnosis, prognosis, detection of recurrence, and evaluation of therapy of colorectal cancer. In: Krebs BP, Lalanne CM, Schneider M, eds. Clinical Application of Carcinoembryonic Antigen Assay, International Congress Series, no. 439. Amsterdam: Excerpta Medica; 1978: 64-79.

153. Beatty JD, Romero C, Brown PW, et al Clinical value of carcinoembryonic antigen: diagnosis, prognosis, and follow-up of patients with cancer. Archives of Surgery 114(5): 563-567; 1979.

154. Arnaud JP, Koehl C, Adloff M. Carcinoembryonic antigen (CEA) in diagnosis and prognosis of colorectal carcinoma. Diseases of the Colon \& Rectum 23(3): 141-144; 1980.

155. Goslin R, Steele G Jr, Macintyre J, et al. The use of preoperative plasma CEA levels for the Stratification of patients after curative resection of colorectal cancers. Annals of Surgery 192(6): 747-751; 1980.

156. Wolmark N, Fisher B, Wieand HS, et al. The prognostic significance of preoperative carcinoembryonic antigen levels in colorectal cancer. Results from NSABP (National Surgical Adjuvant Breast and Bowel Project) clinical trials. Annals of Surgery 199(4): 375-382; 1984.

157. Midiri G, Amanti C, Consorti F, et al. Usefulness of preoperative CEA levels in the assessment of colorectal cancer patient stage. Journal of Surgical Oncology 22(4): 257-260; 1983.

158. Lewi H, Blumgart LH, Carter DC, et al. Pre-operative carcino-embryonic antigen and survival in patients with colorectal cancer. British Journal of Surgery 71(3): 206-208; 1984.

159. Onetto M, Paganuzzi M, Secco GB, et al. Preoperative carcinoembryonic antigen and prognosis in patients with colorectal cancer. Biomedicine \& Pharmacotherapy 39(7): 392-395; 1985.

160. Aabo K, Pedersen H, Kjaer M. Carcinoembryonic antigen (CEA) and alkaline phosphatase in progressive colorectal cancer with special reference to patient survival. European Journal of Cancer \& Clinical Oncology 22(2): 211-217; 1986. 
161. Lazorthes F, Chiotasso P, Roques J, et al. [Postoperative surveillance of rectal cancer]. Revue du Praticien 36(41): 2389-2395; 1986.

162. Armitage NC, Davidson A, Tsikos D, et al. A study of the reliability of carcinoembryonic antigen blood levels in following the course of colorectal cancer. Clinical Oncology 10(2): 141-147; 1984.

163. Herrera MA, Chu TM, Holyoke ED, et al. CEA monitoring of palliative treatment for colorectal carcinoma. Annals of Surgery 185(1): 23-30; 1977.

164. Evans JT, Mittelman A, Chu M, et al. Pre- and postoperative uses of CEA. Cancer 42(3 Suppl): 1419$1421 ; 1978$.

165. Kohler JP, Simonowitz D, Paloyan D. Preoperative CEA level: a prognostic test in patients with colorectal carcinoma. American Surgeon 46(8): 449-452; 1980.

166. Staab HJ, Anderer FA, Brummendorf T, et al. Prognostic value of preoperative serum CEA level compared to clinical staging. I. Colorectal carcinoma. British Journal of Cancer 44(5): 652-662; 1981.

167. Nap M, Mollgard K, Burtin P, et al. What is oncodevelopmental about carcinoembryonic antigen? Tumour Biology 6: 329; 1985.

168. Herrera MA, Chu TM, Holyoke ED. Carcinoembryonic antigen (CEA) as a prognostic and monitoring test in clinically complete resection of colorectal carcinoma. Annals of Surgery 183(1): 5-9; 1976.

169. Lavin PT, Day J, Holyoke ED, et al. A statistical evaluation of baseline and follow-up carcinoembryonic antigen in patients with resectable colorectal carcinoma. Cancer 47(4): 823-826; 1981.

170. Steele G Jr, Ellenberg S, Ramming K, et al. CEA monitoring among patients in multi-institutional adjuvant G.I. therapy protocols. Annals of Surgery 196(2): 162-169; 1982.

171. Northover J. Carcinoembryonic antigen and recurrent colorectal cancer. Gut 27(2): 117-122; 1986.

172. Barone C, Astone A, Cassano A, et al. Advanced colon cancer: staging and prognosis by CEA test. Oncology 47(2): 128-132; 1990.

173. Stamatiadis AP, St. Toumanidou M, Vyssoulis GP, et al. Value of serum acute-phase reactant proteins and carcinoembryonic antigen in the preoperative staging of colorectal cancer. A multivariate analysis. Cancer 65(9): 2055-2057; 1990.

174. Chu TM, Nemoto T. Evaluation of carcinoembryonic antigen in human mammary carcinoma. Journal of the National Cancer Institute 51(4):1119-1122; 1973.

175. Falkson HC, Van Der Watt JJ, Portugal MA, et al. Carcinoembryonic antigen in patients with breast cancer: an adjunctive tool to monitor response and therapy. Cancer 42(3): 1308-1313; 1978.

176. Haagensen DE Jr, Kister SJ, Panick J, et al. Comparative evaluation of carcinoembryonic antigen and gross cystic disease fluid protein as plasma markers for human breast carcinoma. Cancer 42(3 Suppl): 1646$1652 ; 1978$.

177. Pompecki R, Schroder G, Garbrecht M, et al. Frahm H. [Carcinoembryonic antigens (CEA) in patients with metastatic breast cancer under endocrine and therapeutic treatment Deutsche Medizinische Wochenschrift 103(14): 620-622; 1978. 
178. Tormey DC, Waalkes TP. Clinical correlation between CEA and breast cancer. Cancer 42 (3 Suppl): 1507-1511; 1978.

179. Waalkes TP, Gehrke CW, Tormey DC, et al. Biologic markers in breast carcinoma. IV. Serum fucoseprotein ratio. Comparisons with carcinoembryonic antigen and human chorionic gonadotrophin. Cancer 41(5): 1871-1882; 1978.

180. Shousha S, Lyssiotis T, Godfrey VM, et al. Carcinoembryonic antigen in breast-cancer tissue: a useful prognostic indicator. British Medical Journal 1(6166): 777-779; 1979.

181. Cantwell B, Duffy MJ, Fennelly JJ, et al. Carcino-embryonic antigen assay as a guide to tumour bulk, response to therapy and prognosis in human breast cancer. Irish Journal of Medical Science 149(12): 469$474 ; 1980$.

182. Khoo SK, Warner NL, Lie JT, et al. Carcinoembryonic antigen activity of tissue extracts: a quantitative study of malignant and benign neoplasms, cirrhotic liver, normal adult and fetal organs. International Journal of Cancer 11(3): 681-687; 1973.

183. Bezwoda W, Derman D, Bothwell T, et al. Significance of serum concentrations of carcinoembryonic antigen, ferritin, and calcitonin in breast cancer. Cancer 48(7): 1623-1628; 1981.

184. Chatal JF, Chupin F, Ricolleau G, et al. Use of serial carcinoembryonic antigen assays in detecting relapses in breast cancer involving high risk of metastasis. European Journal of Cancer 17(2): 233-238; 1981.

185. Cillari E, Bellavia A, Romano GC, et al. Carcinoembryonic antigen as a monitor in breast cancer. American Journal of Reproductive Immunology 1:269; 1981.

186. Mansour EG, Hastert M, Park CH, et al. Tissue and plasma carcinoembryonic antigen in early breast cancer. A prognostic factor. Cancer 51(7): 1243-1248; 1983.

187. Mughal AW, Hortobagyi GN, Fritsche HA, et al. Serial plasma carcinoembryonic antigen measurements during treatment of metastatic breast cancer. Journal of the American Medical Association 249(14): 1881$1886 ; 1983$.

188. Lang BA, Kocent A, Nekulova M, et al. Three-year follow-up of carcinoembryonal antigen levels in the serum of patients with breast cancer. Neoplasma 31(1): 79-87; 1984.

189. Palazzo S, Liquori V, Molinari B, et al. The role of carcinoembryonic antigen in the postmastectomy follow-up of primary breast cancer and in the prognostic evaluation of disseminated breast cancer. Tumori 70(1): 57-59; 1984.

190. Palazzo S, Liquori V, Molinari B. Is the carcinoembryonic antigen test a valid predictor of response to medical therapy in disseminated breast cancer? Tumori 72(5): 515-518; 1986.

191. Zimmerman W, Ortlieb B, Rudert F et al. Chromosomal localization of the CEA gene family and differential expression in various tumors. XV Annual Meeting of the Society for Oncodevelopmental Biology and Medicine, August 30- September 3, 1987. Abstract 134.

192. Wang DY, Bulbrook RD, Hayward JL, et al. Relationship between plasma carcinoembryonic antigen and prognosis in women with breast cancer. European Journal of Cancer 11(9): 615-618; 1975.

193. Tormey DC, Davis TE, Waalkes TP. Tumor markers. In: Carter SJ, Glatstein E, Livingston RB, eds. 
Principles of Cancer Treatment. New York: McGraw-Hill; 1982: 170.

194. Neville AM, Patel S, Capp M, et al. The monitoring role of plasma CEA alone and in association with other tumor markers in colorectal and mammary carcinoma. Cancer 42(3 Suppl): 1448-1451; 1978.

195. Coombes RC, Powles TJ, Gazet JC, et al. Assessment of biochemical tests to screen for metastases in patients with breast cancer. Lancet 1(8163): 296-297; 1980.

196. Ikeda Y, Oomori H, Koyanagi N, et al. Prognostic value of combination assays for CEA and CA 19-9 in gastric cancer. Oncology 52(6): 483-486; 1995.

197. Concannon JP, Dalbow MH, Hodgson SE, et al. Prognostic value of preoperative carcinoembryonic antigen (CEA) plasma levels in patients with bronchogenic carcinoma. Cancer 42(3 Suppl): 1477-1483; 1978.

198. Stokes TC, Stevens JFS, Long P, et al. Preoperative carcinoembryonic antigen and survival after resection of lung cancer. British Journal of Diseases of the Chest 74(4): 390-394; 1980.

199. Mach JP, Vienny H, Jaeger P et al. Long-term follow-up of colorectal carcinoma patients by repeated CEA radioimmunoassay. Cancer 42(3 Supple): 1439-1447; 1978.

200. Shani A, OíConnell MJ, Moertel CG et al. Serial plasma carcinoembryonic antigen measurements in the management of metastatic colorectal carcinoma. Annals of Internal Medicine 88(5): 627-630; 1978.

201. Sugarbaker PH, Bloomer WD, Corbett ED, et al. Carcinoembryonic antigen (CEA): its role as a monitor of radiation therapy for colorectal cancer. Cancer 42(3 Suppl): 1434-1436; 1978.

202. Wanebo JH, Stearns M, Schwartz MK. Use of CEA as an indicator of early recurrence and as a guide to a selected second-look procedure in patients with colorectal cancer. Annals of Surgery 188(4): 481-493; 1978.

203. Goldenberg DM, Neville M, Carter AC, et al. Carcinoembryonic antigen: its role as a marker in the management of cancer. A National Institutes of Health Consensus Development Conference. Annals of Internal Medicine 94(3): 407-409; 1981.

204. Szymendera JJ, Nowacki MP, Szawlowski AW, et al. Predictive value of plasma CEA levels: preoperative prognosis and postoperative monitoring of patients with colorectal carcinoma. Diseases of the Colon and Rectum 25(1): 46-52; 1982.

205. Molina R, Filella X, Pique JM, et al. Application of the tumor markers CEA and CA 19-9 in the early diagnosis of recurrence of colorectal cancer. Neoplasia 6: 156-158; 1989.

206. Moertel CG, Schutt A J, Go VLW. Carcinoembryonic antigen test for recurrent colorectal carcinoma. Inadequacy for early detection. Journal of the American Medical Association 239(11): 1065-1066; 1978.

207. Moertel, CG, Fleming, TR, MacDonald JS, et al. An evaluation of the carcinoembryonic antigen (CEA) test for monitoring patients with resected colon cancer. Journal of the American Medical Association 270(8): 943-947; 1993.

208. Bruinvels DJ, Stiggelbout AM, Kievit J, et al. Annals of Surgery 219: 174; 1994.

209. Wood CB, Ratcliffe JG, Burt RW, et al. The clinical significance of the pattern of elevated serum carcinoembryonic antigen (CEA) levels in recurrent colorectal cancer. British Journal of Surgery 67(1): 46- 
$48 ; 1980$.

210. Beart RW Jr, O'Connell MJ. Post-operative follow-up of patients with carcinoma of the colon. Mayo Clinic Proceedings 58(6): 361-363; 1983.

211. Beart RW Jr, Metzger PP, O'Connell MJ, et al. Post-operative screening of patients with carcinoma of the colon. Diseases of the Colon and Rectum 24(8): 585-588; 1981.

212. Boey J, Cheung HC, Lai CK et al. A prospective evaluation of serum carcinoembryonic antigen (CEA) levels in the management of colorectal carcinoma. World Journal of Surgery 8(3): 279-286; 1984.

213. Denstman F, Rosen L, Khubchandani IT, et al. Comparing predictive decision rules in postoperative CEA monitoring. Cancer 58(9): 2089-2095; 1986.

214. Coveney EC, Geraghty JG, Sherry F, et al. The clinical value of CEA and CA 15-3 in breast cancer management. International Journal of Biological Markers 10(1): 35-41; 1995.

215. Molina R, Zanon G, Filella X, et al. Use of serial carcinoembryonic antigen and CA 15.3 assays in detecting relapses in breast cancer patients. Breast Cancer Research and Treatment 36(1): 41-48; 1995.

216. Jager W, Kramer S, Palapelas V, et al. Breast cancer and clinical utility of CA 15-3 and CEA. Scandinavian Journal of Clinical and Laboratory Investigation 221 (Suppl.): 87-92; 1995.

217. Holzel WG, Beer R, Deschner W, et al. Individual reference ranges of CA 15-3, MCA and CEA in recurrence of breast cancer. Scandinavian Journal of Clinical and Laboratory Investigation 221 (Suppl.): 93$101 ; 1995$.

218. Diez M, Gomez A, Hernando F, et al. Serum CEA, CA 125, and SCC antigens and tumor recurrence in resectable non-small cell lung cancer. International Journal of Biological Markers 10(1): 5-10; 1995.

219. Lokich JJ, Zamcheck N, Lowenstein M. Sequential carcinoembryonic antigen levels in the therapy of metastatic breast cancer: a predictor and monitor of response and relapse. Annals of Internal Medicine 89(6): 902-906; 1978.

220. Ahlemann LM, Staabb HJ, Anderer FA. Serial CEA determinations as an aid in postoperative therapy management of patients with early breast cancer. Biomedicine 32(4):

194-199; 1980.

221. Andrew SM, Pimm MV, Perkins AC, et al. Comparative imaging and biodistribution studies with an anti-CEA monoclonal antibody and its $\mathrm{F}(\mathrm{ab})_{2}$ and Fab fragments in mice with colon carcinoma xenografts. European Journal of Nuclear Medicine 12(4): 168-175; 1986.

222. Burgess RE. Carcinoembryonic antigen (letter). Annals of Internal Medicine 104(6): 888; 1986.

223. Gropp C, Havemann K, Lehmann FG. Carcinoembryonic antigen and ferritin in patients with lung cancer before and during therapy. Cancer 42(6): 2802-2808; 1978.

224. Aroney RS, Dermody WC, Aldenderfer P, et al. Multiple sequential biomarkers in monitoring patients with carcinoma of the lung. Cancer Treatment Reports 68(6): 859-866; 1984.

225. Krischke W, Niederle N, Schütte J, et al. Is there any clinical relevance of serial determinations of serum carcinoembryonic antigen in small cell lung cancer patients? Cancer 62(7): 1348-1354; 1988. 
226. Vider M, Kashmiri R, Hunter L, et al. Carcinoembryonic antigen (CEA) monitoring in the management of radiotherapeutic patients. Oncology 39(4): 257-72; 1974.

227. Sugarbaker PH, Bloomer WD, Corbett ED, et al. Carcinoembryonic antigen (CEA) monitoring of radiation therapy for colorectal cancer. American Journal of Roentgenology 127(4): 641-644; 1976.

228. Mayer RJ, Garnick MB, Steele GD Jr., et al. Carcinoembryonic antigen (CEA) as a monitor of chemotherapy in disseminated colorectal cancer. Cancer 42(3 Suppl): 1428-1433; 1978.

229. Shinkai T, Saijo N, Tominaga K, et al. Serial plasma carcinoembryonic antigen measurement for monitoring patients with advanced lung cancer during chemotherapy. Cancer 57(7): 1318-1323; 1986.

230. Primus FJ, Clark CA, Goldenberg DM. Immunohistochemical detection of carcinoembryonic antigen. In DeLellis RA, ed. Diagnostic Immunohistochemistry. New York: Masson; 1981: 263.

231. DeLellis RA, Lee AK. Imunohistochemistry of carcinoembryonic antigen--an overview. Journal of Clinical Immunoassay 7: 125; 1984.

232. Pavelic ZP, Petrelli NJ, Herrera L, et al. D-14 monoclonal antibody to carcinoembryonic antigen: immunohistochemical analysis of formalin-fixed, paraffin-embedded human colorectal carcinoma, tumors of non-colorectal origin and normal tissues. Journal of Cancer Research and Clinical Oncology 116(1): 51-56; 1990.

233. Robertson JF, Ellis IO, Bell J, et al. Carcinoembryonic antigen immunocytochemistry in primary breast cancer. Cancer 64(8): 1638-1645; 1989.

234. Bepler G, Ostholt M, Neumann K, et al. Carcinoembryonic antigen as differentiation marker for small cell lung cancer in vitro and its clinical relevance. Anticancer Research 9(6): 1525-1530; 1989.

235. Duk JM, DeBruijn HW, Groenier KH, et al. Adenocarcinoma of the uterine cervix. Prognostic significance of pretreatment serum CA 125, squamous cell carcinoma antigen, and carcinoembryonic antigen levels in relation to clinical and histopathologic tumor characteristics. Cancer. 65(8): 1830-1837; 1990.

236. Dowling GP, Kelly JK. The histogenesis of adenocarcinoma of the gallbladder. Cancer. 58(8): 1702$1708 ; 1986$.

237. Mori M, Ambe K, Adachi Y, et al. Prognostic value of immunohistochemically identified CEA, SC, AFP, and S-100 protein-positive cells in gastric carcinoma. Cancer 62(3): 534-540; 1988.

238. Shimiuzu M, Saitoh Y, Ohyanagi H, et al. Immunohistochemical staining of pancreatic cancer with Cal9-9, KMOl, unabsorbed CEA, and absorbed CEA. A comparison with normal pancreas and chronic pancreatitis. Archives of Pathology and Laboratory Medicine 114(2): 195-200; 1990.

239. Wong MA, Yazdi HM. Hepatocellular carcinoma versus carcinoma metastatic to the liver. Value of stains for carcinoembryonic antigen and naphthylamidase in fine needle aspiration biopsy material. Acta Cytologica 34(2): 192-196; 1990.

240. Nap M. Carcinoembryonic antigen (CEA), problems and perspectives. Bulletin du Cancer 73: 325; 1986.

241. Nap M, Mollgard K, Burtin P, et al. Immunohistochemistry of the carcino-embryonic antigen in the embryo, fetus and adult. Tumor Biology 9(2-3): 145-153; 1988. 
242. Smets G, Warson F, Dehou M-F, et al. Metastasizing neuroendocrine carcinoma of the larynx with calcitonin and somatostatin secretion and CEA production, resembling medullary thyroid carcinoma. Virchows Archiv. A: Pathology. Pathologische Anatomie 416(6): 539-543; 1990.

243. Denk H, Tappeiner G, Eckerstorfer R, et al. Carcinoembryonic antigen (CEA) in gastrointestinal and extragastrointestinal tumors and its relationship to tumor-cell differentiation. International Journal of Cancer. 10(2): 262-272; 1972.

\section{Sorokin JJ, Sugarbaker PH, Zamcheck N, et al. Serial}

carcinoembryonic antigen assays. Use in detection of cancer recurrence. Journal of the American Medical Association 228(1): 49-53; 1974.

245. Shousha S, Lyssiotis T. Correlation of carcinoembryonic antigen in tissue sections with spread of mammary carcinoma. Histopathology 2(6): 433-447; 1978.

246. Wagener C, Muller-Wallraf R, Nisson S, et al. Localization and concentration of carcinoembryonic antigen (CEA) in gastrointestinal tumors: correlation with CEA levels in plasma. Journal of the National Cancer Institute 67(3): 539-547; 1981.

247. Ahnen DJ, Nakane PK, Brown WR. Ultrastructure localization of carcinoembryonic antigen in normal intestine and colon cancer: abnormal distribution of CEA on the surfaces of colon cancer cells. Cancer 49(10): 2077-2090; 1982.

248. Kojima O, Kurimoto T, Uehara Y, et al. Elevation of plasma carcinoembryonic antigen levels in colorectal cancer patients: correlation with carcinoembryonic antigen concentration and localization tissues. Journal of Experimental Clinical Cancer Research 4: 389; 1983.

249. Hamada Y, Yamamura M, Hioki K, et al. Immunohistochemical study of carcinoembryonic antigen in patients with colorectal cancer. Correlation with plasma carcinoembryonic antigen levels. Cancer 55(1): 136$141 ; 1985$

250. Cunningham L, Stocking B, Halter SA, et al. Immunoperoxidase staining of carcinoembryonic antigen as a prognostic indicator in colorectal carcinoma. Diseases of the Colon and Rectum 29(2): 111-116; 1986.

251. Page M, Dalifard I, Bertrand G, et al. Immunostaining of colorectal cancer with monoclonal anti-CEA antibodies compared to serum and tumor CEA content. Anticancer Research 6(5): 893-896; 1986.

252. Martinez V, Azzopardi JG. Invasive lobular carcinoma of the breast: incidence and variants. Histopathology 3(6): 467-488; 1979.

253. Bocker W, Schweikhart G, Pollow K, et al. Immunohistochemical demonstration of carcinoembryonic antigen (CEA) in 120 mammary carcinomas and its correlation with tumour type, grading, staging plasmaCEA, and biochemical receptor status. Pathology, Research and Practice 180(5): 490-497; 1985.

254. Lind HM, Haghighi P. Carcinoembryonic antigen staining in choriocarcinoma. American Journal of Clinical Pathology 86(4): 538-540; 1986.

255. Bordes M, Michiels R, Martin F. Detection by immunofluorescence of carcinoembryonic antigen in colonic carcinoma, other malignant or benign tumors, and non-cancerous tissues. Digestion 9(2): 106-115; 1973. 
256. Rognum T, Elgjo K, Brandtzaeg P, et al. Plasma carcino- embryonic antigen concentrations and immunohistochemical patterns of epithelial marker antigens in patients with large bowl carcinoma. Journal of Clinical Pathology 35(9): 922-933; 1982.

257. Goslin R, O'Brien MJ, Steele G, et al. Correlation of plasma CEA and CEA tissue staining in poorly differentiated colorectal cancer. American Journal of Medicine 71(2): 246-253; 1981.

258. Jetha N, Woo ML, Nanji A. CEA content of colonic polyps (letter). American Journal of Clinical Pathology 85(2): 255; 1986.

259. Davidson BR, Sams VR, Styles J, et al. Comparative study of carcinoembryonic antigen and epithelial membrane antigen expression in normal colon, adenomas and adenocarcinomas of the colon and rectum. Gut 30(9): 1260-1265; 1989.

260. Fischbach H, Mössner J, Syeschab H, et al. Tissue carcinoembryonic antigen and DNA aneuploidy in precancerous and cancerous colorectal lesions. Cancer 65(8): 1820-1824; 1990.

261. Scheele PM, Bendon RW, Ray MB. Carcinoembryonic antigen, alpha l-antitrypsin, trypsin, and alphafetoprotein in the pancreas of patients with cystic fibrosis. Archives of Pathology and Laboratory Medicine 113(10): 1142-1146; 1989.

262. Fritsche R, Mach J-P. Isolation and characterization of carcinoembryonic antigen (CEA) extracted from normal human colon mucosa. Immunochemistry 14(2): 119-127; 1977.

263. Quentmeier A, Moller P, Schwarz V, et al. Carcinoembryonic antigen, CA 19-9, and CA 125 in normal and carcinomatous human colorectal tissue. Cancer 60(9): 2261-2266; 1987.

264. Savoie SC, Sikorska HM. Immunohistochemical characterization of a new anti-carcinoembryonic antigen monoclonal antibody. Anticancer Research 11(1): 1-12; 1991.

265. Breborowicz J, Easty GC, Birbeck M, et al. The monolayer and organ culture of human colorectal carcinomata and the associated "normal" colonic mucosa and their production of carcinoembryonic antigens. British Journal of Cancer 31(5):

$559-569 ; 1975$.

266. Kuroki M, Arakawa F, Yamamoto H, et al. Active production and membrane anchoring of carcinoembryonic antigen observed in normal colon mucosa. Cancer Letters 43(1-2): 151-157; 1988.

267. Matsuoka Y, Endo K, Kawamura Y, et al. Normal bronchial mucus contains high levels of cancerassociated antigens, CA125, CA19-9, and carcinoembryonic antigen. Cancer 65(3): 506-510; 1990.

268. Allum WH, Stokes HJ, MacDonald F, et al. Demonstration of carcinoembryonic antigen (CEA) expression in normal, chronically inflamed, and malignant pancreatic tissue by immunohistochemistry. Journal of Clinical Pathology 39(6):

610-614; 1986.

269. Wahren B, Lidbrink E, Wallgren A, et al. Carcinoembryonic antigen and other tumor markers in tissue and serum or plasma of patients with primary mammary carcinoma. Cancer 42(4): 1870-1878; 1978.

270. Walker RA. Demonstration of carcinoembryonic antigen in human breast carcinomas by the immunoperoxidase technique. Journal of Clinical Pathology 33(4): 356-360; 1980. 
271. Van der Linden JC, Baak JPA, Lindeman J, et al. Carcinoembryonic antigen expression and peanut agglutinin binding in primary breast cancer and lymph node metastases; lack of correlation with clinical histopathological, biochemical, and morphometric features. Histopathology 9: 1051-1059; 1985.

272. Von Kleist S, Wittekind C, Sandritter E, et al. CEA positivity in sera and breast tumor tissues obtained from the same patients. Pathology, Research and Practice 173(14): 390-401; 1982.

273. Gilchrist KW, Kalish MA, Gould VE, et al. Immunostaining for carcinoembryonic antigen does not discriminate for early recurrence in breast cancer. The ECOG experience. Cancer 56(2): 351-355; 1985.

274. Persijn JP, Korsten CB. Carcino-embryonic antigens, oestrogen receptors and androgen receptors in human breast tumors: clinical evaluation of carcino-embryonic antigen, IV. Journal of Clinical Chemistry and Clinical Biochemistry 15(10): 553-556; 1977.

275. Nasierowska-Guttmejer A, Szawlowski A. Immunohisto- chemical detection of carcinoembryonic antigen (CEA) in

non-cancerous and cancerous gastric mucosa. International Journal of Biological Markers 4(1): 8-12; 1989.

276. Sehested M, Hirsch FR, Hou-Jensen K. Immunoperoxidase staining for carcinoembryonic antigen in small cell carcinoma of the lung. European Journal of Cancer \& Clinical Oncology 17(10): 1125-31; 1981.

277. Nanbu Y, Fujii S, Konishi I, et al. Immunohistochemical localizations of CA 125, carcinoembryonic antigen, and

CA-19-9 in normal and neoplastic glandular cells of the uterine cervix. Cancer 62(12): 2580-2588; 1988.

278. Charpin C, Bhan AK, Zurawski VR Jr, et al. Carcinoembryonic antigen (CEA) and carbohydrate determinant 19-9 (CA 19-9) localization in 121 primary and metastatic ovarian tumors: an immunohistochemical study with the use of monoclonal antibodies. International Journal of Gynecological Pathology 1(3): 231-245; 1982.

279. Fleuren GJ, Nap M. Second European conference on clinical Oncology. Amsterdam: November 2-5, 1983.

280. Nap M, Keuning H, Burtin P, et al. CEA and NCA in benign and malignant breast tumors. American Journal of Clinical Pathology 82(5): 526-534; 1984.

281. Pressman D, Korngold L. The in vivo localization of anti-Wagner-osteogenic-sarcoma antibodies. Cancer 6: 619; 1953.

282. Reif AE, Curtis LE, Duffield R, et al. Trial of radiolabeled antibody localization in metastases of a patient with a tumor containing carcinoembryonic antigen (CEA). Journal of Surgical Oncology 6(2): 133$150 ; 1974$.

283. Primus FJ, Wang RJ, Goldenberg DM, et al. Localization of human GW-39 tumors in hamsters by radiolabeled heterospecific antibody to carcinoembryonic antigen. Cancer Research 33(11): 2977-2982; 1973.

284. Goldenberg DM, Preston DF, Primus FJ, et al. Photoscan localization of GW-39 tumors in hamsters using radiolabeled anti-carcinoembryonic antigen immunoglobulin G. Cancer Research 34(1): 1-9; 1974.

285. Dillman RO, Beauregard JC, Sobol RE, et al. Lack of radioimmunodetection and complications associated with monoclonal anticarcinoembryonic antigen antibody cross-reactivity with an antigen on circulating cells. Cancer Research 44(5): 2213-2218; 1984. 
286. Goldenberg DM, Deland F, Kim E, et al. Use of radiolabeled antibodies to carcinoembryonic antigen for the detection and localization of diverse cancers by external photoscanning. New England Journal of Medicine 298(25): 1384-1386; 1978.

287. Goldenberg DM, Sharkey RM, Primus FJ. Immunocytochemical detection of carcinoembryonic antigen in conventional histopathology specimens. Cancer 42(3 Suppl): 1546-1553; 1978.

288. Goldenberg DM, Kim EE, Deland FH, et al. Radioimmunodetection of cancer with radioactive antibodies to carcinoembryonic antigen. Cancer Reseach 40(8 Pt 2): 2984-2992; 1980

289. Mach JP, Forni M, Ritschard J, et al. Use and limitations of radiolabeled anti-CEA antibodies and their fragments for photoscanning detection of human colorectal carcinomas. Oncodevelopmental Biology and Medicine 1(1): 49-69; 1980.

290. Wahl RL, Parker CW, Philpott GW. Improving radioimaging and tumor localization with monoclonal $\left.\mathrm{F}(\mathrm{ab})_{2}\right)_{2}$. Journal of Nuclear Medicine 24(4): 316-325; 1983.

291. Bradwell AR, Fairweather DS, Dykes PW, et al. Limiting factors in the localization of tumours with radiolabelled antibodies. Immunology Today 6: 163; 1985.

292. Sullivan DC, Silva JS, Cox CE, et al. Localization of I-131-labeled goat and primate anti carcinoembryonic antigen (CEA) antibodies in patients with cancer. Investigative Radiology 17(4): 350-355; 1982.

293. Beatty JD, Duda RB, Williams LE, et al. Preoperative imaging of colorectal carcinoma with ${ }^{111}$ In-labeled anti carcinoembryonic antigen monoclonal antibody. Cancer Research 46: 6494-6502; 1986.

294. Duda RB, Beatty JD, Sheibani K, et al. Imaging of human colorectal adenocarcinoma with indium-labeled anti carcinoembryonic antigen monoclonal antibody. Archives of Surgery 12l(11): 1315-1319; 1986.

295. Goldenberg DM, Goldenberg H, Sharkey RM, et al. Clinical studies of cancer radioimmunodetection with carcinoembryonic antigen monoclonal antibody fragments labeled with $123-\mathrm{I}$ or ${ }^{99 \mathrm{~m}} \mathrm{Tc}$. Cancer Research 50(Suppl): 909S-921S; 1990.

296. Dykes PW, Hine KR, Bradwell AR, et al. Localisation of tumour deposits by external scanning after injection of radiolabelled anti-carcinoembryonic antigen. British Medical Journal 280(6209): 220-222; 1980.

297. Berche C, Mach JP, Lumbroso JD, et al. Tomoscintigraphy for detecting gastrointestinal and medullary thyroid cancers: first clinical results using radiolabelled monoclonal antibodies against carcinoembryonic antigen. British Medical Journal 285(6353): 1447-1451; 1982.

298. Fairweather DS, Bradwell AR, Dykes PW, et al. Improved tumour localisation using indium-111 labelled antibodies. British Medical Journal 287: 167-170; 1983.

299. Allum WH, MacDonald F, Anderson P, et al. Localisation of gastrointestinal cancer with a ${ }^{131}$ I labelled monoclonal antibody to CEA. British Journal of Cancer 53(2): 203-210; 1986.

300. Armitage NC, Perkins AC, Durrant LG, et al. In vitro binding and in vivo localization in colorectal cancer of a high affinity monoclonal antibody to carcinoembryonic antigen. British Journal of Surgery 
73(12): 965-969; 1986.

301. Holzheimer RGA, Muhrer KH, Muller H, et al. Immunoscintigram with monoclonal antibodies of liver metastases of colorectal cancer. British Journal of Cancer 54: 537-538; 1986.

302. Paganelli G, Riva P. Sarti G, et al. Intraperitoneal versus intravenous injection of radiolabelled monoclonal antibodies in patients with colorectal carcinoma. British Journal of Cancer 54: 542; 1986.

303. Vanderick J, Leners N, Ferrant A, et al. Tumour imaging with indium and I-labelled anti-CEA antibodies. British Journal of Cancer 54: 534; 1986.

304. Abdel-Nabi HH, Schwartz AN, Higano CS, et al. Colorectal carcinoma: detection with indium-11l anticarcinoembryonic antigen monoclonal antibody ZCE-O25. Radiology 164(3):

617-621; 1987.

305. Abdel-Nabi HH, Schwartz AN, Goldfogel G, et al. Colorectal tumors: scintigraphy with In-111 antiCEA monoclonal antibody and correlation with surgical, histopathologic, and immunohistochemical findings. Radiology 166(3): 747-752; 1988.

306. Henze E, Kübel R, Waitzinger J, et al. Tumor scintigraphy with ${ }^{131}$ I anti-CEA monoclonal antibodies and $\mathrm{F}(\mathrm{ab})_{2}$ in colorectal cancer. European Journal of Nuclear Medicine 13(3): 125-129; 1987.

307. Edington HD, Watson CG, Levine G, et al. Radioimmuno- imaging of metastatic medullary carcinoma of the thyroid gland using an indium-111-labeled monoclonal antibody to CEA. Surgery 104(6): 1004-1010; 1988.

308. Patt YZ, Lamki LM, Haynie TP, et al. Improved tumor localization with increasing dose of indium-111labeled anti-carcinoembryonic antigen monoclonal antibody ZCE-025 in metastatic colorectal cancer. Journal of Clinical Oncology 6(8): 1220-1230; 1988.

309. Riva P, Moscatelli G, Paganelli G, et al. Antibody-guided diagnosis: an Italian experience on CEAexpressing tumours. International Journal of Cancer 2(Suppl): 114-120; 1988.

310. Siccardi AG, Buraggi GL, Callegaro L. Immunoscintigraphy of adenocarcinomas by means of radiolabeled $\mathrm{F}(\mathrm{ab}) 2$ fragments of an anti-carcinoembryonic antigen monoclonal antibody: a multicenter study. Cancer Research 49(11):3095-3103, 1989.

311. Doerr RJ, Abdel-Nabi H, Merchant B. Induim-111 ZCE-025 immunoscintigraphy in occult recurrent colorectal cancer with elevated carcinoembryonic antigen level. Archives of Surgery 125(2): 226-229; 1990.

312. Kairemo KJ. Immunolymphoscintigraphy with ${ }^{99 m}$ Tc-labeled monoclonal antibody (BW431/26) reacting with carcinoembryonic antigen in breast cancer. Cancer Research 50(3 Suppl): 949S-954S; 1990.

313. Sharkey RM, Goldenberg DM, Goldenberg H, et al. Murine monoclonal antibodies against carcinoembryonic antigen: immunological, pharmacokinetic and targeting properties in humans. Cancer Research 50(9): 2823-2831; 1990.

314. Lamki LM, Haynie TP, Murray JL, et al. The effect of increasing unlabelled monoclonal antibody $(\mathrm{MoAb})$ doses on metastases detection and on body distribution of various ${ }^{111}$ In MoAbs. British Journal of Cancer 54: 535; 1986. 
315. Moscatelli G, Agostini M, Benni S, et al. Antibody-guided detection of primary medullary carcinoma by means of indium labelled anti-CEA monoclonal antibody: a case report. British Journal of Cancer 54: 554; 1986.

316. Chatal JF, Saccavini JC, Fumoleau P, et al. Immunoscintigraphy of colon carcinoma. Journal of Nuclear Medicine 25(3): 307-314; 1984.

317. Wong JYC, Mivechi NF, Paxton RJ, et al. The effects of hyperthermia on tumor carcinoembryonic antigen expression. International Journal of Radiation Oncology, Biology, Physics 17(4): 803-808; 1989.

318. Ichiki S, Kuroki M, Matsunaga A, et al. Antigenic alterations of carcinoembryonic antigens involved in the secretion from various human tumor cell lines. Japanese Journal of Cancer Research 77(11): 1005-1011; 1986.

319. Pimm MV, Perkins AC, Armitage NC, et al. The characteristics of blood-borne radiolabels and the effect of anti-mouse IgG antibodies on localization of radiolabeled monoclonal antibody in cancer patients. Journal of Nuclear Medicine 26(9): 1011-1023; 1985.

320. Schroff RW, Foon KA, Beatty SM, et al. Human anti-murine immunoglobulin responses in patients receiving monoclonal antibody therapy. Cancer Research 45(29): 879-885; 1985.

321. Traub UC, DeJager RL, Primus FJ, et al. Antiidiotype antibodies in cancer patients receiving monoclonal antibody to carcinoembryonic antigen. Cancer Research 48: 4002-4006; 1988.

322. Hagan PL, Halpern SE, Chen A, et al. In vivo kinetics of radiolabeled monoclonal anti-CEA antibodies in animal models. Journal of Nuclear Medicine 26(12): 1418-1423; 1985.

323. Steinstrasser A and Oberhausen E. Anti-CEA labelling kit

BW 431/26. Results of the European multicenter trial. Nuklearmedizin 34(6): 232-242; 1995.

324. Takenoshita S, Hashizume T, Asao T, et al. Immunoscintigraphy using 99mTc-labeled anti-CEA monoclonal antibody for patients with colorectal cancer. Anticancer Research 15(2):471-475; 1995.

325. Begent RHJ, Verhaa, MJ, Chester KA, et al. Clinical evidence of efficient tumor targeting based on single-chain Fv antibody selected from a combinatorial library. Nature Medicine 2(9):979-984; 1996.

326. Hughes K, Pinsky CM, Petrelli NJ, et al. Use of carcinoembryonic antigen radioimmunodetection and computed tomography for predicting resectability of recurrent colorectal cancer. Annals of Surgery 1997 [In press].

327. Rainsbury RM. The localization of human breast carcinomas by radiolabelled monoclonal antibodies. British Journal of Surgery 71(10): 805-812; 1984.

328. Rosner D, Nabi H, Panaro V, et al. Immunoscintigraphy may reduce the number of surgical biopsies in women with benign breast disease and indeterminate mammograms: A novel approach. Proceedings of the American Society of Clinical Oncology 15:102; 1996 [Abstract].

329. Silverberg E. Cancer statistics, 1983. Ca: a Cancer Journal for Clinicians 33(1): 9-25; 1983.

330. Sikorska H, Shuster J, Gold P. Clinical applications of carcinoembryonic antigen (review). Cancer Detection and Prevention 12: 321-355; 1988. 
331. Hodge JW, McLaughlin JP, Abrams SI, et al. Admixture of recombinant vaccinia virus containing the gene for the costimulatory molecule $\mathrm{B} 7$ and a recombinant vaccinia virus containing a tumor-associated antigen gene results in enhanced specific T-cell responses and antitumor immunity. Cancer Research 55(116): 3598-3603; 1995.

332. Conry RM, LoBuglio AF, Loechel F, et al. A carcinoembryonic antigen polynucleotide vaccine for human clinical use. Cancer Gene Therapy 2(1): 33-38; 1995.

333. Richards CA, Austin EA, Huber BE. Transcriptional regulatory sequences of carcinoembryonic antigen: identification and use with cytosine deaminase for tumor-specific gene therapy. Human Gene Therapy 6(7): $881-893 ; 1995$.

\section{BIOGRAPHY}

Phil Gold, CC., O.Q., M.D., Ph.D., FRCP(C) is the discoverer of carcinoembryonic antigen (CEA) as a human tumor marker. He is presently Executive Director of the Clinical Research Centre of the Montreal General Hospital (Montreal, QC, Canada), and is the Douglas C. Cameron Professor of Medicine and Professor of Physiology and Oncology at McGill University (Montreal, QC, Canada). His career has encompassed biomedical research, teaching, and patient care. His administrative experience was gained (with some reluctance) as the Inaugural Director of the McGill Cancer Center, Physician-in-Chief of the Montreal General Hospital, and Chair of Medicine at McGill. Dr. Gold is the Faculty Advisor of the McGill Journal of Medicine, and teaching of both students and residents remains his most satisfying activity.

Neil A. Goldenberg is the former Editor-in-Chief of the McGill Journal of Medicine. He graduated from Williams College (Williamstown, MA, USA) in English in 1993 and is currently in the Class of 1998 at the McGill University Faculty of Medicine. He has served on the editorial staff of Genetic Engineering News (New York, NY, USA), and is a member of the American Medical Writers Association. His experience in tumor biology and immunology was gained through research performed at the Garden State Cancer Center (Newark, NJ, USA) and UMD-New Jersey Medical School (Newark, NJ, USA), as well as through two summer research fellowships awarded by the National Institutes of Health (Bethesda, MD, USA).

Copyright (C) 1997 by MJM 